\title{
Laminar Forced Convection Heat Transfer from Laterally Perforated-Finned Heat Sinks
}

\author{
Mohammad Reza Shaeri*, Richard Bonner \\ Advanced Cooling Technologies, Inc., Lancaster, PA 17601
}

\begin{abstract}
Thermal and hydraulic performance of laterally perforated-finned heat sinks (LA-PFHSs) operating in the laminar flow regime were experimentally investigated and compared to that of the solid-finned heat sink (SFHS). Square cross sectional perforations at three different sizes were distributed equidistantly along the length of the LA-PFHSs. For each perforation size, five different porosities were tested. Locally measured thermal resistances at various locations along the heat sink were acquired. The results signify the key roles of geometrical parameters, mainly the fin pitches, on thermal-fluid characteristics of LAPFHSs. The effects of both perforation size and porosity on overall pressure drops were also measured and presented. LA-PFHSs increased the pressure drops due to cavities formed over the perforations. The pressure drag was found to be the dominant pressure drop when compared with friction drag. However, the pressure drops became independent of the porosity beyond a threshold perforation size. Overall, LAPFHSs are promising thermal management solutions to decrease thermal resistance and improve temperature uniformity across the heat sink base at a given pumping power, if the optimum range of porosity is obtained for a given perforation size. The results indicate that weight sensitive applications would be the most promising use for LA-PFHS. A new parameter as the mass-based thermal resistance was defined, and for the cases studied in this paper, over $45 \%$ reduction in the mass-based thermal resistance of the SFHS was achieved using LA-PFHSs with the maximum porosity.
\end{abstract}

Keywords: Heat sink; Perforated fin; Boundary layer interruption; Thermal resistance; Temperature nonuniformity; Low-weight cooling system.

* Corresponding author.

E-mail: mohammadreza.shaeri@1-act.com; oveisshaeri@gmail.com

Telephone: +1-717-295-6057 


\section{Nomenclature}

$d$ : Distance between the plane of the embedded thermocouples and the fin/channel base (m)

$D_{h}=\frac{2 H W_{\mathrm{ch}}}{H+W_{\mathrm{ch}}}:$ Channel hydraulic diameter $(\mathrm{m})$

$H$ : Channel height (m)

$K_{s}$ : Thermal conductivity of the heat sink (W/m.K)

$L$ : Channel length (m)

$L_{P}$ : Perforation length (m)

$L_{\mathrm{TC}}$ : Distance from the embedded thermocouple to the inlet of heat sink (m)

$M$ : Mass of fins $(\mathrm{kg})$

MBTR: Mass-based thermal resistance $(\mathrm{kg} \mathrm{K} / \mathrm{W})$

$N$ : Number of channels

$N_{P}$ : Number of perforations

$N_{R}$ : Number of perforation rows

$P_{p}$ : Pumping power $(\mathrm{W})$

$\Delta P:$ Pressure drop $(\mathrm{Pa})$

$Q_{\text {ch }}$ : Input heat per unit channel length (W)

$Q_{\text {input: }}$ Electrical input heat (W)

$R_{\mathrm{ch}}$ : Local thermal resistance inside the channel (K/W)

$R_{\mathrm{HS}}$ : Heat sink thermal resistance $(\mathrm{K} / \mathrm{W})$

Re: Channel Reynolds number

$S_{x}$ : Horizontal distance between adjacent perforations (m)

$S_{y}$ : Vertical distance between adjacent perforations (m)

$t_{b}$ : Heat sink base thickness (m)

$t_{f}:$ Fin thickness (m)

$T_{b}$ : Heat sink base temperature $(\mathrm{K})$

$T_{f}$ : Local air temperature inside the channel (K)

$T_{\text {film: }}:$ Film temperature (K)

$T_{i}$ : Inlet air temperature $(\mathrm{K})$

$T_{o}$ : Outlet air temperature $(\mathrm{K})$

$T_{s}:$ Fin/channel base temperature (K)

$U:$ Approach velocity $(\mathrm{m} / \mathrm{s})$

$\dot{V}_{\text {ch }}:$ Volume flowrate inside the channel $\left(\mathrm{m}^{3} / \mathrm{s}\right)$ 
$\dot{V}_{t}$ : Volume flowrate inside the air $\operatorname{duct}\left(\mathrm{m}^{3} / \mathrm{s}\right)$

$W$ : Heat sink width $(\mathrm{m})$

$W_{\text {ch: }}$ Channel width (m)

\section{Greek symbols}

$\beta$ : A percentage of change in the MBTR of the SFHS

$\eta$ : Porosity effectiveness

$\theta$ : Normalized temperature non-uniformity

$\mu$ : Dynamic viscosity (Pa.s)

$\rho:$ Air density $\left(\mathrm{kg} / \mathrm{m}^{3}\right)$

$\phi$ : Porosity

\section{Subscripts}

avg: Average

$j$ : The $j$ th embedded thermocouple

LA-PFHS: Lateral perforated-finned heat sink

max: Maximum

min: Minimum

SFHS: Solid-finned heat sink

\section{Introduction}

Air-cooled heat sinks have been widely used as primary thermal management solutions due to their low cost and simplicity. However, these cooling devices are suffering from low heat transfer coefficients because of low air density. Practically, such limitations cannot be resolved by increasing the air velocity since the airflow is usually laminar or weakly turbulent in air-cooled heat sinks because of constraints in space and pumping power [1].

Generally, the thermal-fluid characteristics of any air-cooled system are dictated by the thickness of the boundary layer that is formed over the surface [2]. Since the boundary layer acts as a stationary insulating layer, interrupting the boundary layer in order to avoid its growth over the surface potentially improves the thermal characteristics of the air-cooled system. There are different techniques to interrupt the boundary layer, including wavy fins [3, 4], louvered fins [5, 6], offset strip fins [7, 8], vortex generators $[9,10]$, grooved channels $[11,12]$, pin fins $[13,14]$, converging-diverging channels $[15,16]$, and 
perforated fins. However, since perforated fins result in lighter devices because of perforations, they are particularly attractive in weight sensitive applications.

Perforated-finned heat sinks are made by leveraging perforated fins in the heat sink construction, mainly by implementing two types of perforations either along the length of the fins or on the lateral surfaces of the fins; the corresponding heat sinks are called the longitudinally perforated-finned heat sink (LOPFHS), and the laterally perforated-finned heat sink (LA-PFHS), respectively. The heat transfer enhancement in a LO-PFHS is mainly due to an increase in the heat transfer area since each longitudinal perforation makes a channel along the fin length. Generally, fabrication of these heat sinks is costly and requires a complicated manufacturing technique because commonly used industrial heat sinks employ extremely thin fins with high aspect ratios. Related studies about LO-PFHSs including studies by the authors can be found in [17-26]. However, unlike LO-PFHSs, the mechanism of heat transfer rate in LAPFHSs is based on the frequent interrupting the boundary layer, as such, the boundary layer terminates and restarts over the perforations. Also, LA-PFHSs have the advantage that they can be fabricated through relatively simple and low-cost manufacturing techniques. Investigating the thermal characteristics of LA-PFHSs is the focus of the present study.

Although the thermo-fluid transport phenomena in a solid-finned heat sink (SFHS, a regular/imperforated heat sink) have been well-documented and characterized through relatively accurate correlations, such knowledge is limited in LA-PFHSs. This is due to complex thermo-fluid physics in these devices and lack of detailed and fundamental research in this field. The related research efforts by the present authors in $[27,28]$ were among the first comprehensive studies to illustrate the flow structures over the perforations. Shaeri et al. [27, 28] computationally studied turbulent and laminar heat transfer as well as flow streamlines in LA-PFHSs with square cross sectional perforations by considering a broad range of perforation sizes and porosities. They illustrated recirculation inside the perforations, as well as different sizes of wakes that were formed behind the heat sinks. In addition, Shaeri et al. [27, 28] studied the effects of perforations on the individual friction drag and pressure drag, as well as the temperature distributions across the surface of the fins. In conclusion, correlations were developed for the average Nusselt number as a function of both Reynolds numbers and porosity. However, these correlations are not physics-based and were developed by curve-fitting of the computational results. The studies performed in $[27,28]$ were motivations for further research in this field, as such, Ismail et al. [29] repeated the study by Shaeri et al. [27] only by changing the geometry of perforations from square to circular, hexagonal, and triangular cross sections, through a computational research. Willockx [30] extended the study by Shaeri et al. [27], and applied the inverse heat conduction problem (IHCP) technique to a solid fin, and fins with one and two lateral perforations, respectively. However, in their experiments, a systematic error appeared in the temperature measurements for perforated fins due to the camera lens reflection, which affected the 
accuracy of the IHCP solution in their experiments. Nevertheless, Willockx [30] confirmed the results obtained by Shaeri et al. [27] about the thinning of the boundary layer due to a negative pressure gradient in the perforation. Dhanawade et al. [31, 32] experimentally tested LA-PFHSs, and reported enhancement in heat transfer coefficients, by relying on the exposed area of the LA-PFHSs (including the surfaces inside the perforations). Enhancement in heat transfer rates from LA-PFHSs by relying on the open area of LA-PFHSs is reported in other studies, such as experimental works by Al-Doori [33]. Also, there are several studies about laterally perforated fins implemented on circular tubes. Karabacak and Yakar [34], Lee et al. [35], and Banerjee et al. [36] investigated the effects of angular positions of perforations on circular fins located on tubes. Liu et al. [37] numerically investigated the effects of both perforation sizes and number on the airside $j$ factor and heat transfer rates from finned-tube heat exchangers that were equipped with lateral perforated fins with large fin pitches. They reported that an optimal perforation design can be obtained to achieve the maximum increase in the $j$ factor, compared with imperforatedfinned tubes. However, the thermo-fluid physics in a LA-PFHS could be different from that in the configurations of perforated heat exchangers presented in [34-37], due to a frequent interruption in the boundary layer along the surfaces of relatively long fins in a LA-PFHS.

The lack of fundamental research in LA-PFHSs resulted in limited understanding of thermo-fluid transport phenomena in these cooling devices. Although in our studies at [27, 28], the open area of the LA-PFHSs were used to correlated their Nusselt numbers, comparison of Nusselt numbers based on the open area of LA-PFHSs may lead to under/overestimated thermal performances, due to a monotonic change in the open area by increasing the porosity. Such an inaccurate approach to calculate Nusselt number was adopted in several research as reviewed above, and resulting increased heat transfer rates were reported as the evidence to introduce LA-PFHSs as efficient cooling devices. Moreover, the frequent terminating and restarting the boundary layer over the perforations result in a complex and unpredictable entrance length. As such, the flow inside the channel of a LA-PFHS may never become fully developed. Therefore, using the conventional correlations that were already derived based on the thermo-fluid transport phenomena of SFHSs may not be accurate to describe heat transfer coefficients in LA-PFHSs. The lack of sufficient knowledge about physics of flow and heat transfer in LA-PFHSs, and the nonexistence of a valid method to report thermal characteristics of LA-PFHSs have hindered commercialization of these devices.

Recently, the authors [38] showed the capability of LA-PFHSs to improve cooling performances of a heat sink without any penalty in pumping power. However, in that study, we did not describe the detailed of flow and heat transfer in LA-PFHSs. Besides, that study was performed for a limited number of perforation sizes and porosities. 
In this study, more details about thermo-fluid characteristics of LA-PFHSs, along with industrial benefits of these cooling systems are presented through experiments. The present study presents the first published experimental data regarding the local thermal characteristics of LA-PFHSs. Also, it is shown that the conventional correlations that are derived for SFHSs are not suitable for predicting the thermal performances of LA-PFHSs. The present experiments cover three different perforation sizes, and five porosities for each perforation size. The accuracy of the experimental results are validated by comparing the raw experimental data with available correlated values in the literature. In addition, through three different parameters, the industrial merits of LA-PFHSs are illustrated and classified, depending on the design goal in a specific application. The findings in this study are our motivations to disclose more details of thermo-fluid physics in LA-PFHSs through our ongoing relevant research.

\section{Experiment}

\subsection{Experimental setup}

Figs. 1(a) and 1(b) illustrate the CAD model of the experimental setup, and the exploded view of the setup in this study, respectively. The heat sink is numbered as 1 in Fig. 1 (b). A centrifugal blower (RG90-18/12N, ebm-papst Inc.) provided the airflow through a $91 \mathrm{~cm}$ long stainless steel duct with a rectangular cross section of $7.3 \mathrm{~cm}$ by $4.3 \mathrm{~cm}$. The air velocities inside the duct were adjusted by regulating voltages of a 0-30 VDC power supply (CSI3005X5, Circuit Specialists, Inc.) that powered the blower. Two resistance temperature detectors (RTD) probes (PR-26A-3-100-A-1/8-0600-M12-1, OMEGA Engineering, Inc.) at the entrance and exit of the heat sink measured the inlet and outlet air temperatures, respectively. The duct, blower, inlet, and outlet RTDs are numbered as 2, 3, 4, and 5, respectively, in Fig. 1 (b). A differential pressure transducer (DPT) (PX653-01D5V, OMEGA Engineering, Inc.) measured the pressure drop across the duct. The high and low-pressure sensors of the DPT were located between the blower and the heat sink entrance (number 6 in Fig. 1(b)), and at the exit of the duct (number 7 in Fig. 1(b)), respectively. Since the pressure drop between the fan and the entrance of the heat sink, as well as that between the exit of heat sink and the duct exit was negligible, the DPT location upstream and downstream of the duct did not affect the measured pressure drop across the heat sink. The top surface of the duct was formed by placing a transparent polycarbonate cover on the duct flange. The duct was completely airtight by placing an adhesive neoprene rubber gasket between the flange and the polycarbonate cover, which was clamped in place between the cover and the flange. The rubber gasket and polycarbonate cover are numbered as 8, and 9, respectively, in Fig. 1(b).

The CAD model of a LA-PFHS with two rows of perforations is illustrated in Fig. 2. Heat sinks were made of 6063-T5 aluminum alloy, and included 19 parallel channels (20 fins) with the fin thickness at $0.96 \mathrm{~mm}$, and the channel length, height, and width at $203 \mathrm{~mm}, 22.86 \mathrm{~mm}$, and $2.18 \mathrm{~mm}$, respectively. 
The thickness of the heat sink base was at $2.54 \mathrm{~mm}$ as well. Perforations with square cross sections were fabricated on the lateral surfaces of the fins through the electrical discharge machining technique.

Experiments were conducted using 16 heat sinks whose parameters are summarized in Table 1. The SFHS (shown as Solid in Table 1) was used as the base for comparisons. In Table 1, each LA-PFHS is recognized by two numbers, as the first number represents the porosity, and the second number inside the parenthesis as the perforation size in $\mathrm{mm}$. The porosity is defined as the ratio of void volume of the fins due to perforations, to the volume of the solid fin (without perforation), as follows:

$\phi=\frac{N_{P} L_{P}^{2}}{H L}$

In this study, LA-PFHSs covered porosities ranging from 0.15 to 0.55 , and three perforation sizes at 5.08 $\mathrm{mm}, 7.62 \mathrm{~mm}$, and $15.24 \mathrm{~mm}$, for a given porosity.

Table 1. Geometrical information of the perforations associated with the different heat sinks in this study.

\begin{tabular}{|l|l|l|l|l|l|l|}
\hline Heat sink & $N_{P}$ & $L_{P}(\mathrm{~mm})$ & $S_{x}(\mathrm{~mm})$ & $S_{y}(\mathrm{~mm})$ & $N_{R}$ & $\phi$ (porosity) \\
\hline Solid & 0 & $\mathrm{n} / \mathrm{a}$ & $\mathrm{n} / \mathrm{a}$ & $\mathrm{n} / \mathrm{a}$ & $\mathrm{n} / \mathrm{a}$ & 0 \\
\hline $0.15(5.08)$ & 27 & 5.08 & 15.75 & 1.91 & 3 & 0.15 \\
\hline $0.15(7.62)$ & 12 & 7.62 & 25.4 & 2.54 & 2 & 0.15 \\
\hline $0.15(15.24)$ & 3 & 15.24 & 39.37 & $\mathrm{n} / \mathrm{a}$ & 1 & 0.15 \\
\hline $0.25(5.08)$ & 45 & 5.08 & 7.87 & 1.91 & 3 & 0.25 \\
\hline $0.25(7.62)$ & 20 & 7.62 & 11.43 & 2.54 & 2 & 0.25 \\
\hline $0.25(15.24)$ & 5 & 15.24 & 20.32 & $\mathrm{n} / \mathrm{a}$ & 1 & 0.25 \\
\hline $0.35(5.08)$ & 63 & 5.08 & 4.32 & 1.91 & 3 & 0.35 \\
\hline $0.35(7.62)$ & 28 & 7.62 & 6.35 & 2.54 & 2 & 0.35 \\
\hline $0.35(15.24)$ & 7 & 15.24 & 12.07 & n/a & 1 & 0.35 \\
\hline $0.45(5.08)$ & 81 & 5.08 & 2.34 & 1.91 & 3 & 0.45 \\
\hline $0.45(7.62)$ & 36 & 7.62 & 3.56 & 2.54 & 2 & 0.45 \\
\hline $0.45(15.24)$ & 9 & 15.24 & 6.60 & n/a & 1 & 0.45 \\
\hline $0.55(5.08)$ & 99 & 5.08 & 1.04 & 1.91 & 3 & 0.55 \\
\hline $0.55(7.62)$ & 44 & 7.62 & 1.52 & 2.54 & 2 & 0.55 \\
\hline $0.55(15.24)$ & 11 & 15.24 & 2.95 & n/a & 1 & 0.55 \\
\hline & & & & & & \\
\hline
\end{tabular}

As shown in Fig. 3, five grooves at different distances from the inlet of the heat sink $\left(L_{\mathrm{TC}}\right)$ were machined on the heat sink base. Five T-type thermocouples (TJC36-CPSS-032G-12, OMEGA Engineering, Inc.) 
were placed in these grooves, and the spaces between the thermocouples and the grooves were filled with a bonding resin. The vertical distance from the center of grooves to the heat sink base was $1.4 \mathrm{~mm}$. Information regarding locations of thermocouples is provided in Table 2 . A $51 \mathrm{~mm} \times 203 \mathrm{~mm}$ insulated flexible heater (KH-208/10-P, OMEGA Engineering, Inc.) was glued on the heat sink base, and provided a uniform heat load to the heat sink base. The heater was powered by a variable transformer (3PN116C, 0-140 V, 10 Amps, Superior Electric). The supplied voltage and current to the heater were measured using a multi-meter (FLUKE 117 TRUE RMS), and a clamp meter (FLUKE 376 TRUE RMS), respectively. In order to minimize the heat loss to the ambient, the floor of the duct, as well as the sides of the heat sinks, were covered by thermal insulation layers. The insulation layers at the floor of the duct, and around the heat sink are numbered as 10, and 11, respectively, in Fig. 1(b). A Keithley 2700 data acquisition system collected signals from the thermocouples, RTDs, and differential pressure transducer.

Table 2. locations of five thermocouples and their distances from each other on the heat sink base.

\begin{tabular}{|c|c|c|c|c|c|}
\hline$L_{\mathrm{TC}, 1}(\mathrm{~cm})$ & $L_{\mathrm{TC}, 2}(\mathrm{~cm})$ & $L_{\mathrm{TC}, 3}(\mathrm{~cm})$ & $L_{\mathrm{TC}, 4}(\mathrm{~cm})$ & $L_{\mathrm{TC}, 5}(\mathrm{~cm})$ & Lateral distances $(\mathrm{cm})$ \\
\hline 2.54 & 6.35 & 10.16 & 13.97 & 17.78 & $\begin{array}{l}\text { - Heat sink edge to the closest } \\
\text { thermocouple: } 0.94 \mathrm{~cm} \\
\text { - Between adjacent } \\
\text { thermocouples: } 1.05 \mathrm{~cm}\end{array}$ \\
\hline
\end{tabular}

An individual test included measuring the data at a specific input blower voltage and an input heat. The data was collected for three minutes of operation after reaching a steady state condition. Steady state was considered to be reached when the changes in the temperatures obtained by individual embedded thermocouples and RTDs were below $0.2^{\circ} \mathrm{C}$ over a 10 -minute period of operation. The experiments were proceeded by increasing the input blower voltage from $8 \mathrm{~V}$ to $14 \mathrm{~V}$, by increments in $1 \mathrm{~V}$, at a fixed input heat load. This process was repeated until all the input blower voltages and input heat loads were tested for all heat sinks. The experiment were conducted at two heat inputs of $50 \mathrm{~W}$, and $100 \mathrm{~W}$. Also, the excellent repeat of experimental results were obtained for over three months.

In order to determine the airflow rates inside a heat sink, the setup in Fig. 1(a) was connected to the airflow bench (AMCA 210-99) to obtain the actual operating point (AOP) of the heat sink at an individual blower voltage using an appropriate nozzle diameter in the airflow bench. Note that slight differences in the presented results in this study compared with those in our previous study [38] are due to the change in airflow rate measurement techniques, since the flow rates inside the heat sinks in [38] were obtained through the theoretical operating points, which led to less accurate flow rates compared with those obtained by AOPs. 
When the volume flow rate inside the duct $\left(\dot{V}_{t}\right)$ was determined, the volume flow rate, approach velocity, and Reynolds number associated with an individual channel are calculated as follows:

$$
\begin{gathered}
\dot{V}_{\mathrm{ch}}=\frac{\dot{V}_{t}}{N} \\
U=\frac{\dot{V}_{\mathrm{ch}}}{W_{\mathrm{ch}} H} \\
\operatorname{Re}=\frac{\rho U D_{h}}{\mu}
\end{gathered}
$$

where $\mathrm{Re}$ is calculated using the air properties at the film temperature, shown below:

$$
T_{\text {film }}=\frac{T_{i}+T_{s, \text { avg }}}{2}
$$

where $T_{s, \text { avg }}$ is the average fin/channel base temperature, and is calculated using the assumption of onedimensional heat diffusion in a distance $d$, which is the distance between the plane of the embedded thermocouple and the fin/channel base [39]:

$$
T_{s, \text { avg }}=\frac{\sum_{i=1}^{M} T_{b, i}}{M}-\frac{Q_{\text {input }} d}{K_{s} L W} \quad, \quad M=5
$$

which $d=1.4 \mathrm{~mm}$, and $Q_{\text {input }}$ is the electrical input heat that will be described in the next section. The pumping power is calculated as follows:

$$
P_{p}=\dot{V}_{t} \times \Delta P
$$

\subsection{Data reduction}

The heat loss $\left(Q_{\text {loss }}\right)$ from the heat sink to the ambient is calculated by subtracting the sensible absorbed heat by the air $\left(Q_{\text {conv }}\right)$ from the electrical input heat $\left(Q_{\text {input }}\right)$, as follows:

$$
Q_{\text {loss }}=Q_{\text {input }}-Q_{\text {conv }}=I \times V-\left[\rho \dot{V}_{t} c_{p}\left(T_{o}-T_{i}\right)\right]
$$

where $I$ and $V$ are the current and voltage, respectively, provided by the variable transformer to the heater, and $c_{p}$ is the air specific heat. Eq (8) is calculated at the inlet air density. The heat loss in the present experiments ranged from 4.2-9.3\%. As a result, it is assumed that the whole input heat was absorbed by the heat sink; therefore, $Q_{\text {input }}$ is used for the data reduction.

Similar to the strategy for calculating $T_{s, \text { avg }}$ in Eq (6), the fin/channel base temperature at the location of the $j$ th embedded thermocouple is calculated as follows: 
$T_{s, j}=T_{b, j}-\frac{Q_{\mathrm{input}, j} d}{K_{s} L_{\mathrm{TC}, j} W}$

where $W \times L_{\mathrm{TC}, j}$ is the surface area from the inlet of the heat sink to the location of the $j$ th embedded thermocouple, and $\mathrm{Q}_{\text {input }, j}$ is the input heat over this area, calculated as follows:

$Q_{\text {input }, j}=Q_{\text {input }} \frac{L_{\mathrm{TC}, j}}{L}$

The local air temperature at the location of $j$ th embedded thermocouple is calculated by writing a heat balance equation over the control volume that is formed from the inlet of the heat sink to the location of the $j$ th thermocouple, as shown below:

$T_{f, j}=\frac{Q_{\text {input }, j}}{\rho \dot{V}_{t} c_{p}}+T_{i}$

Since the exact heat transfer area of a LA-PFHS is unknown, a local thermal resistance inside the channel and at the location of the $j$ th thermocouple is calculated in this study, instead of heat transfer coefficients because their calculations require understanding the heat transfer area:

$R_{\mathrm{ch}, j}=\frac{T_{s, j}-T_{f, j}}{Q_{\mathrm{ch}}}$

where $Q_{\text {ch }}$ is the input heat per unit channel length for a given channel that is composed of the channel width, plus half of the thickness of fins, as shown in Fig. 4 [39]:

$Q_{\mathrm{ch}}=\frac{Q_{\text {input }}}{L W}\left(W_{\mathrm{ch}}+t_{f}\right)$

In this paper, thermal performances of LA-PFHSs in heat flux controlled experiments are presented through three parameters that are directly calculated from raw experimental data, and are independent of any unknown parameter such as the heat transfer area. Therefore, these parameters are informative enough to describe overall cooling performances of LA-PFHSs. The first parameter is the heat sink thermal resistance, as shown below:

$$
R_{\mathrm{HS}}=\frac{T_{b, \max }-T_{i}}{Q_{\text {input }}}
$$

Since the heat input is the same among all the heat sinks within a heat flux controlled experiment, $R_{\mathrm{HS}}$ describes the excess heat sink temperature, as such, a smaller $R_{\mathrm{HS}}$ stands for an overall cooler heat sink to dissipate a fixed amount of heat.

The second parameter to report cooling performances of LA-PFHSs is the normalized temperature nonuniformity as follows: 
$\theta=\frac{T_{b, \max }-T_{b, \min }}{T_{i}}$

where $T_{b, \max }$ and $T_{b, \min }$ are the maximum and minimum temperatures at the heat sink base, respectively, recorded by the embedded thermocouples in the heat sink base. Unlike our previous study in [38] that the temperature non-uniformity was described by using $T_{s, \text { avg }}$ instead of the inlet air temperature, Eq (15) leads to a more accurate temperature drop in a heat sink base since $T_{i}$ is an independent variable, while $T_{s, \text { avg }}$ depends on both $T_{b, \max }$ and $T_{b, \text { min. }}$.

For the third parameter to compare cooling performances of LA-PFHSs with those of a SFHS, we define a new parameter as the mass-based thermal resistance (MBTR), which is calculated by multiplication of the heat sink thermal resistance by its mass, as follows:

$\mathrm{MBTR}=M R_{\mathrm{HS}}$

where $M$ corresponds to the heat sink mass, excluding the mass of heat sink base.

All three parameters provided by Eqs (14)-(16) are independent from each other. As a result, depending on design priority, each of these parameters can be used as an evaluating factor to compare cooling performances of LA-PFHSs with those of a SFHS. For applications that require overall cooler heat sinks to dissipate a given heat load, Eq (14) is an appropriate parameter. Eq (15) is useful in applications that are sensitive to temperature variations across the heat source, and finally, Eq (16) is sufficiently informative in applications with constraints in weight.

\subsection{Uncertainty analysis}

The uncertainty of the property $R$ that is a function of variables $X_{1}, X_{2}, \ldots, X_{\mathrm{i}}$, is calculated as follows [40]:

$\delta R=\left[\sum_{i=1}^{N}\left(\frac{\partial R}{\partial X_{i}} \delta X_{i}\right)^{2}\right]^{\frac{1}{2}}$

where $\delta X_{i}$ stands for the uncertainty of the $i$ th measured value. Tables 3 and 4 list the uncertainties of the measured values and calculated values, respectively.

Table 3. Uncertainty of the measured values.

\begin{tabular}{|l|l|}
\hline RTD & $\pm(0.15+0.002 t)^{\circ} \mathrm{C}$, which $t$ is the temperature in ${ }^{\circ} \mathrm{C}$. \\
\hline T-type thermocouples & $\pm 0.5^{\circ} \mathrm{C}$ \\
\hline Differential pressure transducer & $0.3 \%$ of full scale \\
\hline
\end{tabular}




\begin{tabular}{|l|l|}
\hline Dimensions & $\pm 2.54 \times 10^{-2} \mathrm{~mm}$ \\
\hline Airflow bench & $\pm 2 \%$ of the measured flow rate \\
\hline Variable transformer & $\pm 2 \%$ of the voltage \\
\hline
\end{tabular}

Table 4. Maximum uncertainty of the calculated values.

\begin{tabular}{|l|l|}
\hline Parameter & Maximum uncertainty (\%) \\
\hline$Q_{\text {input }}(\mathrm{W})$ & 2.00 \\
\hline$\theta$ & 0.55 \\
\hline$Q_{\mathrm{ch}}(\mathrm{W})$ & 2.30 \\
\hline$U(\mathrm{~m} / \mathrm{s})$ & 2.32 \\
\hline$P_{p}(\mathrm{~W})$ & 2.46 \\
\hline $\operatorname{Re}$ & 2.55 \\
\hline$T_{s, j}(\mathrm{~K})$ & 1.16 \\
\hline$T_{f, j}(\mathrm{~K})$ & 1.42 \\
\hline$R_{\mathrm{ch}, j}(\mathrm{~K} / \mathrm{W})$ & 6.67 \\
\hline$R_{\mathrm{HS}}(\mathrm{K} / \mathrm{W})$ & 3.22 \\
\hline
\end{tabular}

\section{Validation of experiments}

The accuracy of the present experiments are assessed by comparing the experimental pressure drops and Nusselt numbers resulting from the SFHS, against correlated values, as illustrated in Fig. 5. The correlations are presented in the Appendix. The maximum difference between experimental and correlated pressure drops, and that between the experimental and correlated Nusselt numbers are below $9.4 \%$, and $8.0 \%$, respectively. The excellent agreements between experimental and correlated values indicate the good accuracy of the present experiments. Moreover, the excellent agreements in Fig. 5(a) prove the precise locations of the high and low pressure sensors of the differential pressure transducer in the duct.

\section{Results and discussions}

To evaluate the significance of the natural convection heat transfer in the present experiments, the Richardson number (Ri), as the ratio of the Grashof number to the square of Reynold number, is calculated for individual heat sinks, as follows [21, 24]: 
$\mathrm{Ri}=\frac{g\left(\frac{1}{\frac{T_{i}+T_{s, \text { avg }}}{2}+273.15}\right)\left(T_{b, \max }-T_{i}\right) H}{U^{2}}$

where $g$ is the gravitational acceleration, and the first and second terms inside the parentheses correspond the thermal expansion coefficient, and the maximum temperature difference in the experiment, respectively. For the operating conditions in this study, the maximum Richardson number is less than 0.003 that indicates the forced convection as the dominant mode of heat transfer in the present experiments $[21,24]$.

Fig. 6 illustrates the pressure drops due to a change in porosity at a given perforation size, at different Reynolds numbers. For easier inter-graph comparisons, the scale of the axes is maintained unchanged among all graphs. Although all the heat sinks were tested at the same input blower voltages, different flow resistances in the heat sinks resulted in various flow rates and, in turn, a different range of Reynolds numbers, as observed in Fig. 6. Generally, a LA-PFHS increases the pressure drops due to more disturbance of the flow inside the channels compared with a SFHS. However, while the monotonic enhancement in pressure drops by increasing the porosity (number of perforations) is distinguishable for the smallest perforations $\left(L_{P}=5.08 \mathrm{~mm}\right)$, pressure drops become almost independent of porosity for larger perforations. This is probably associated with more frequent boundary layer interruptions resulting from an increase in the number of perforations in both horizontal (along the fin) and vertical configurations. An interesting finding in Fig. 6(a) is that by increasing the porosity, the pressure drops become larger while the solid lateral surfaces of the fins decrease monotonically. This indicates that the pressure drops in LAPFHSs are less influenced by the frictional drag, but is mainly affected by the pressure drag. In fact, each perforation acts like a cavity that creates recirculation zones inside and over the perforation. The significance of the pressure drag on the total drag resulted from a cavity was demonstrated by Gatski and Grosch [41]. The flow structures and recirculation zones inside and over perforations were illustrated in the previous research by the author [28], as shown in Fig. 7.

Fig. 8 illustrates the effects of perforation sizes on pressure drops, at the smallest, intermediate, and the largest porosities in this study. It is expected that pressure drops increase monotonically by adding the number of perforations at a given porosity, due to more frequent boundary layer interruptions. This is observed for all perforation sizes at porosities 0.35 and 0.55 . However, at the porosity of 0.15 , although the largest perforations results in smaller pressure drops among other perforations, two small-size perforations show different trends than what is expected, as such, they experience almost the same 
pressure drops at low Reynolds numbers, but the large perforation results in larger pressure drops at higher Reynolds numbers. This unusual trend may be due to either noise in experiments or less sensitivity of pressure drops to slight changes in a perforation size at low porosities. The latter claim would probably be more valid since not only the pressure drops resulting from $L_{P}=5.08 \mathrm{~mm}$ are larger than those obtained from $L_{P}=7.62 \mathrm{~mm}$ in all Reynolds numbers at the porosity of 0.35 , but also their gaps become wider at the porosity of 0.55 . Therefore, Fig. 8 indicates that there probably is a threshold porosity that beyond that, the changes in pressure drops resulting from a slight change in a perforation size becomes significant. However, more detailed research along with flow visualizations is required to address the effects of geometrical parameters such as horizontal and vertical distances between adjacent perforations $\left(S_{x}\right.$, and $\left.S_{y}\right)$, as well as the number of perforation rows $\left(N_{R}\right)$ on the frequent boundary layer interruption and, in turn, resulting pressure drops.

As shown in Figs. 6 and 8, LA-PFHSs experience a lower range of Reynolds numbers than that of the SFHS. However, due to negligible changes in the density of air through the entire experiments among all heat sinks at a given heat load (less than $2.7 \%$ deviation in air density), a lower range of Reynolds numbers corresponds to a lower range of volume flow rates. As a result, despite their increased pressure drops, LA-PFHSs could be potentially promising cooling devices to reduce pumping power. Pumping power as the power required to drive the flow across the heat sink, is one of the key parameters to designing an active cooling system, as such, an increase in pumping power may hinder using the cooling system, regardless of the capability of the system to improve thermal performances. Therefore, in order to present cooling performances of LA-PFHSs in a more applicable way, their thermal characteristics are described as functions of pumping power instead of Reynolds numbers throughout the rest of this study. Local channel thermal resistances at the location of each embedded thermocouple are illustrated through Figs. 9 to 13. For more convenient inter-graph comparisons, the axis scales are maintained the same among all the graphs in a figure. The complicated thermo-fluid physics in LA-PFHSs are clearly observed by complex trends of changes in local $R_{\mathrm{ch}}$ associated with different porosities and perforation sizes. Due to lack of sufficient knowledge about the details of transport phenomena in LA-PFHSs at this moment, all the details provided by Figs. 9-13 may not be interpreted. However, the most notable findings from these figures are presented. For all heat sinks, at a given location in the duct, $R_{\mathrm{ch}}$ decreases by increasing the pumping power since the difference between the channel base temperature and the air temperature becomes smaller by increasing the flow rates. At the beginning of the heat sink, while small-sized perforations at the porosity of 0.35 result in the smallest $R_{\text {ch }}$ (Figs. 9(a) and 9(b)), the $R_{\text {ch }}$ associated with this porosity considerably increases by the largest perforation size (Fig. 9(c)). The same scenario happens at the porosity of 0.25 , but at $L_{\mathrm{TC}}=6.35 \mathrm{~cm}$ (Fig. 10). In addition, it is observed that a LA-PFHS results in different extremes in $R_{\mathrm{ch}}$ at various locations in the heat sink. For example, $R_{\mathrm{ch}}$ resulting from the porosity 
at 0.15 and $L_{P}=5.08 \mathrm{~mm}$ decreases from a moderately large value at the begging of the heat sink (Fig. 9(a)) and reaches to the smallest value at the middle of heat sink (Fig. 11(a)), and again, increases through the end of the heat sink. All of these trends indicate the key role of geometrical parameters, most likely the distance between adjacent perforations, to dictate the thickness of the boundary layer at different locations along the channel length. In fact, decreasing the thermal resistance signifies that the flow is still developing. Such trends indicate the lack of accuracy of conventional correlations that are derived for SFHSs, to correlate heat transfer coefficients in LA-PFHSs, since those correlations ignore the complex trends of entrance length in a LA-PFHS.

Also, almost for all perforation sizes and for entire heat sink locations, the largest porosity leads to the highest $R_{\text {ch. }}$. This indicates an existence of a trade-off between the solid surface area of the fin with the void volume, as such, increasing the porosity beyond that threshold leads to an increased $R_{\mathrm{ch}}$ and, in turn, degradation of thermal performance of the heat sink. Further detailed research in connection with the flow visualization over the perforations is required to address the effects of perforation row, distance between perforations, etc., on flow structures over the perforations and temperature distributions across the heat sinks as well as fin surfaces. The results from Figs. 9-13 are motivations for authors to extend this study to investigate further details of transport phenomena in LA-PFHSs. More results from our ongoing research will be presented in the close future.

Nevertheless, despite the lack of sufficient knowledge about thermo-fluid physics in LA-PFHSs, their overall thermal performances should be identified in order to determine the capability of LA-PFHSs as the potentially efficient thermal management solutions compared with SFHSs. This is performed using correlations provided by Eqs (14), (15), and (16).

Fig. 14 illustrates the effects of changes in a porosity at a given perforation size, on heat sink thermal resistances. Generally, LA-PFHSs are promising thermal management solutions to reduce thermal resistances at a given pumping power, which means LA-PFHSs can handle higher head loads without increasing the pumping power compared with a SFHS. Common trends can be found between $R_{\mathrm{HS}}$ and $R_{\mathrm{ch}}$, such as both the largest $R_{\mathrm{ch}}$ and $R_{\mathrm{HS}}$, for all perforation sizes with the largest porosity. Again, this indicates that increasing a porosity beyond a threshold would deteriorate thermal performances due to removing the most part of conducting path of the fins by perforations. However, due to lack of fundamental research in thermo-fluid physics of LA-PFHSs, making a more valid connection between the trends of $R_{\mathrm{HS}}$ and those of local $R_{\mathrm{ch}}$ would require further detailed investigations. More details in this regard will be provided through our research results in the close future.

The porosity effectiveness is defined as a percentage of change in the thermal resistance of the SFHS by a LA-PFHS, and is correlated as follow: 


$$
\eta=\frac{R_{\mathrm{HS}, \mathrm{LA}-\mathrm{PFHS}}-R_{\mathrm{HS}, \mathrm{SFHS}}}{R_{\mathrm{HS}, \mathrm{SFHS}}} \times 100
$$

To calculate $\eta$, first, $R_{\mathrm{HS} \text {,SFHS }}$ is correlated from the raw experimental data as a function of pumping power, then this function is applied to compute the equivalent $R_{\mathrm{HS}, \mathrm{SFHS}}$ at the pumping power associated with each LA-PFHS. In order to obtain the optimum range of porosities to reduce the heat sink thermal resistance, Fig. 15 illustrates the effectiveness of individual porosity at all perforation sizes, at different pumping powers. This is interesting for industrial applications that require an overall colder heat sink to dissipate a fixed amount of heat. Generally, the porosity at 0.15 , specifically in higher pumping power, reduces the thermal resistance, and the porosity of 0.25 comes next. However, beyond a porosity at 0.25 , LA-PFHSs lead to an increase in the thermal resistance, as such, the porosity of 0.55 enhances $R_{\mathrm{HS}}$ by 15 $20 \%$. Also, an important conclusion from this figure is the inaccurate reporting heat transfer coefficients (h) of LA-PFHSs, by inserting the open area $(A)$ of a LA-PFHS in $h=\frac{Q}{A \Delta T}$; for instance, not only do all LA-PFHSs in this study have a smaller open area than that of a SFHS, but also the open area of a LAPFHS monotonically decreases by increasing the porosity at a given perforation size, which leads to monotonic increases in heat transfer coefficients by increasing the porosity, if open area is inserted in $h=\frac{Q}{A \Delta T}$.

Normalized temperature non-uniformity across the heat sink bases are illustrated in Fig. 16. Generally, LA-PFHSs are promising cooling devices to lead a more uniform temperature distribution across the heat sink base. The LA-PFHS with the porosity at 0.15 and $L_{P}=7.62 \mathrm{~mm}$ improves the temperature nonuniformity by 30\%. As mentioned earlier, Eqs (14)-(16) are independent from each other, as such, a LAPFHS with the lowest thermal resistance does not necessarily lead to the heat sink with the highest temperature uniformity across the heat sink base.

A percentage of change in the MBTR of the SFHS by a LA-PFHS is calculated as shown below:

$$
\beta=\frac{\mathrm{MBTR}_{\mathrm{LA}-\mathrm{PFHS}}-\mathrm{MBTR}_{\mathrm{SFHS}}}{\mathrm{MBTR}_{\mathrm{SFHS}}} \times 100=\frac{R_{\mathrm{HS}, \mathrm{LA}-\mathrm{PFHS}}(1-\phi)-R_{\mathrm{HS}, \mathrm{SFHS}}}{R_{\mathrm{HS}, \mathrm{SFHS}}} \times 100
$$

Fig. 17 provides interesting results for weight sensitive applications, by illustrating the performances of individual porosity at all perforation sizes to offer thermal management solutions with reduced MBTRs. Based on this figure, the MBTR $_{\text {SFHS }}$ is monotonically reduced by increasing the porosity, due to a marked decrease in the mass of the heat sink. One important conclusion from Fig. 17 is that although LA-PFHSs may not seem very interesting due to an additional fabrication cost for inserting perforations to achieve only a slight decrease in $R_{\mathrm{HS}}$ (below $10 \%$ ), they can decrease $\mathrm{MBTR}_{\mathrm{SFHS}}$ between $15 \%$ and over $45 \%$, at a given pumping power. This is significantly valuable in weight sensitive applications like aerospace where mass is a primary concern. 


\section{Conclusion}

Laminar forced convection heat transfer as well as pressure drops in LA-PFHSs were investigated through experiments. LA-PFHSs increase the pressure drops due to cavities formed over perforations. The main component to increase the pressure drop in LA-PFHS is the pressure drag. However, there is a threshold perforation size, as such beyond that limit, the pressure drops become independent of a porosity. In addition, the effects of perforation sizes at a given porosity on pressure drops were discussed, and it was found that beyond a threshold porosity, the pressure drops are sensitive to even slight changes in perforation sizes.

Local $R_{\mathrm{ch}}$ at the locations of embedded thermocouples in the heat sink base were compared among all the heat sinks. Non-predictable trends of local $R_{\mathrm{ch}}$ signify the complex thermo-fluid physics in LA-PFHSs. The distances between adjacent perforations were recognized as the most possible parameter affecting on the boundary interruption and, in turn, complex trends in $R_{\mathrm{ch}}$.

The industrial merits of LA-PFHSs were classified based on three different design priorities in industrial applications. For this purpose, $R_{\mathrm{HS}}$, temperature non-uniformity, and a new parameter as the MBTR were defined, and illustrated for all heat sinks, as functions of pumping power. Generally, LA-PFHSs are promising cooling devices to reduce both heat sink thermal resistance and temperature non-uniformity across the heat sink base, at a given pumping power. However, in order to design an optimum range of porosity to improve thermal performances of heat sinks, further fundamental research is required to address the effects of geometrical parameters on thermo-fluid physics of LA-PFHSs because beyond a threshold porosity, thermal performances are deteriorated, mainly due to removing the most conducting paths of the fins by perforations. In addition, the inaccuracy of conventional approaches in the literature to calculate heat transfer coefficients of LA-PFHSs by using their open area was discussed.

LA-PFHSs are excellent cooling devices for use in weight sensitive applications like the aerospace industry, as such, they result in almost 50\% reduction in MBTR of the SFHS at a given pumping power. Due to lack of fundamental research about thermo-fluid characteristics of LA-PFHSs, still this knowledge is limited in these thermal management solutions. More detailed results to disclose thermal characteristics of LA-PFHSs will be presented through the ongoing research by the authors.

\section{Acknowledgement}

This material is based upon work supported by the National Science Foundation under Grant\# IIP1059286 to the American Society for Engineering Education.

The support extended by the Office of Science in the U.S. Department of Energy, award\# DE-SC0011317 is gratefully acknowledged. 
The authors are thankful to Ms. Abbey Gall for her support to setup the experimental testbed.

\section{Appendix}

The pressure drop across a heat sink is described as follows [42, 43]:

$\Delta P=\frac{\rho U^{2}}{2}\left[K_{c}+K_{e}+4 x^{+} f_{\text {app }} \operatorname{Re}\right]$

with the apparent friction factor and the dimensionless hydrodynamic length as below:

$$
\begin{aligned}
& f_{\text {app }} \operatorname{Re}=\left[\left(\frac{3.44}{\sqrt{x^{+}}}\right)^{2}+(f \operatorname{Re})^{2}\right]^{0.5} \\
& x^{+}=\frac{L}{D_{h} \operatorname{Re}}
\end{aligned}
$$

The Poiseuille number ( $f \mathrm{Re}$ ) for a laminar flow in a rectangular duct is described as follows [44]:

$$
f \operatorname{Re}=24\left(1-1.3553 \alpha+1.9467 \alpha^{2}-1.7012 \alpha^{3}+0.9564 \alpha^{4}-0.2537 \alpha^{5}\right)
$$

where $\alpha$ is the channel aspect ratio that must be less than unity, otherwise its inverse is used. In addition, the sudden contraction loss $\left(K_{c}\right)$ and sudden expansion loss $\left(K_{e}\right)$ are described as follows [42]:

$$
\begin{aligned}
& K_{c}=0.42(1-\varepsilon) \\
& K_{e}=(1-\varepsilon)^{2}
\end{aligned}
$$

where $\varepsilon$ represents the fraction of duct cross section that air passes through, and is calculated as follows:

$$
\varepsilon=\frac{\text { void cross section in the duct }}{\text { duct cross sectional area }}=\frac{N W_{\mathrm{ch}} H}{\text { duct cross sectional area }}
$$

Fig. 5(a) illustrates the comparisons between experimental and predicted pressure drops.

Teertstra et al. [45] proposed the following correlation to predict the Nusselt number in a plate-finned heat sink:

$$
N u_{\text {corr }}=\frac{\tanh \sqrt{2 N u_{i} \frac{K H^{2}}{K_{s} W_{\text {ch }} t}\left(\frac{t}{L}+1\right)}}{\sqrt{2 N u_{i} \frac{K H^{2}}{K_{s} W_{\mathrm{ch}} t}\left(\frac{t}{L}+1\right)}} N u_{i}
$$

where 
$N u_{i}=\left[\frac{1}{\left(\frac{\operatorname{Re}_{b}^{*} \operatorname{Pr}}{2}\right)^{3}}+\frac{1}{\left(0.664 \sqrt{\operatorname{Re}_{b}^{*}} \operatorname{Pr}^{1 / 3} \sqrt{1+\frac{3.65}{\sqrt{\operatorname{Re}_{b}^{*}}}}\right)^{3}}\right]^{-1 / 3}$

where Pr is the Prandtl number, and $\operatorname{Re}_{b}^{*}$ is the Reynolds number that is defined as follows:

$$
\operatorname{Re}_{b}^{*}=\frac{\rho U W_{\mathrm{ch}}}{\mu} \times \frac{W_{\mathrm{ch}}}{L}
$$

In addition, the experimental channel Nusselt number is calculated as shown below [45]:

$$
N u_{\mathrm{ex}}=\frac{\left(\frac{Q_{\mathrm{conv}}}{N}\right) W_{\mathrm{ch}}}{K(2 L H)\left(T_{s, \mathrm{avg}}-T_{i}\right)}
$$

The indices corr and ex in Eqs (A-8) and (A-11) stand for correlation, and experiment, respectively. Fig. 5

(b) illustrates the comparisons between experimental and predicted Nusselt numbers.

\section{References}

[1] Y. Yu, T.W. Simon, M. Zhang, T. Yeom, M.T. North, T. Cui, Enhancing heat transfer in air-cooled heat sinks using piezoelectrically-driven agitators and synthetic jets, International Journal of Heat and Mass Transfer 68 (2014) 184-193.

[2] J.P. Koplow, A fundamentally new approach to air-cooled heat exchangers, SANDIA report No. SAND2009-135192 (2009).

[3] G.W. Kim, H.M. Lim, G.H. Rhee, Numerical studies of heat transfer enhancement by cross-cut flow control in wavy fin heat exchangers, International Journal of Heat and Mass Transfer 96 (2016) 110-117. [4] Y.B. Tao, Y.L. He, J. Huang, Z.G. Wu, W.Q. Tao, Three-dimensional numerical study of wavy finand-tube heat exchangers and field synergy principle analysis, International Journal of Heat and Mass Transfer 50 (2007) 1163-1175.

[5] K. Ryu, K-S. Lee, Generalized heat-transfer and fluid-flow correlations for corrugated louvered fins, International Journal of Heat and Mass Transfer 83 (2015) 604-612.

[6] Z-g. Qi, J-p. Chen, Z-j. Chen, Parametric study on the performance of a heat exchanger with corrugated louvered fins, Applied Thermal Engineering 27 (2007) 539-544.

[7] M-S. Kim, J. Lee, S-J. Yook, K-S. Lee, Correlations and optimization of a heat exchanger with offsetstrip fins, International Journal of Heat and Mass Transfer 54 (2011) 2073-2079. 
[8] K.H. Do, B-I. Choi, Y-S. Han, T. Kim, Experimental investigation on the pressure drop and heat transfer characteristics of a recuperator with offset strip fins for a micro gas turbine, International Journal of Heat and Mass Transfer 103 (2016) 457-467.

[9] M.J. Lawson, K.A. Thole, Heat transfer augmentation along the tube wall of a louvered fin heat exchanger using practical delta winglets, International Journal of Heat and Mass Transfer 51 (2008) 23462360.

[10] A. Sinha, H. Chattopadhyay, A.K. Iyengar, G. Biswas, Enhancement of heat transfer in a fin-tube heat exchanger using rectangular winglet type vortex generators, International Journal of Heat and Mass Transfer 101 (2016) 667-681.

[11] K. Bilen, M. Cetin, H. Gul, T. Balta, The investigation of groove geometry effect on heat transfer for internally grooved tubes, Applied Thermal Engineering 29 (2009) 753-761.

[12] N. Zheng, P. Liu, F. Shan, Z. Liu, W. Liu, Heat transfer enhancement in a novel internally grooved tube by generating longitudinal swirl flows with multi-vortexes, Applied Thermal Engineering 95 (2016) 421-432.

[13] M. Tahat, Z.H. Kodah, B.A. Jarrah, S.D. Probert, Heat transfers from pin-fin arrays experiencing forced convection, Applied Energy 67 (2000) 419-442.

[14] W. Yuan, J. Zhao, C.P. Tso, T. Wu, W. Liu, T. Ming, Numerical simulation of the thermal hydraulic performance of a plate pin fin heat sink, Applied Thermal Engineering 48 (2012) 81-88.

[15] O.B. Kanargi, M. Law, C. Yap, P.S. Lee, Numerical investigation of cross-connected alternating converging-diverging channels, Energy Procedia 75 (2015) 3230-3238.

[16] A.K. Chandra, K. Kishor, P.K. Mishra, Md.S. Alam, Numerical simulation of heat transfer enhancement in periodic converging-diverging microchannel, Procedia Engineering 127 (2015) 95-101.

[17] B. Sahin, A. Demir, Performance analysis of a heat exchanger having perforated square fins, Applied Thermal Engineering 28 (2008) 621-632.

[18] B. Sahin, A. Demir, Thermal performance analysis and optimum design parameters of heat exchanger having perforated pin fins, Energy Conversion and Management 49 (2008) 1684-1695.

[19] A. Al-Damook, N. Kapur, J.L. Summers, H.M. Thompson, An experimental and computational investigation of thermal air flows through perforated pin heat sinks, Applied Thermal Engineering 89 (2015) 365-376.

[20] A. Al-Damook, N. Kapur, J.L. Summers, H.M. Thompson, Computational design and optimisation of pin fin heat sinks with rectangular perforations, Applied Thermal Engineering 105 (2016) 691-703. [21] M.R. Shaeri, M. Yaghoubi, Thermal enhancement from heat sinks by using perforated fins, Energy Conversion and Management 50 (2009) 1264-1270. 
[22] M.R. Shaeri, M. Yaghoubi, Numerical analysis of turbulent convection heat transfer from an array of perforated fins, International Journal of Heat and Fluid Flow 30 (2009) 218-228.

[23] M.R. Shaeri, T-C. Jen, The effects of perforation sizes on laminar heat transfer characteristics of an array of perforated fins, Energy Conversion and Management 64 (2012) 328-334.

[24] M.R. Shaeri, T-C. Jen, Turbulent heat transfer analysis of a three-dimensional array of perforated fins due to changes in perforation sizes, Numerical Heat Transfer, Part A, 61 (2012) 807-822.

[25] K.D. Huang, S-C. Tzeng, T-M. Jeng, J-R. Wang, S-Y. Cheng, K-T. Tseng, Experimental study of fluid flow and heat transfer characteristics in the square channel with a perforation baffle, International Communications in Heat and Mass Transfer 35 (2008) 1106-1112.

[26] D. Sahel, H. Ameur, R. Benzeguir, Y. Kamla, Enhancement of heat transfer in a rectangular channel with perforated baffles, Applied Thermal Engineering 101 (2016) 156-164.

[27] M.R. Shaeri, M. Yaghoubi, K. Jafarpur, Heat transfer analysis of lateral perforated fin heat sinks, Applied Energy 86 (2009) 2019-2029.

[28] M. Yaghoubi, M.R. Shaeri, K. Jafarpur, Three-dimensional numerical laminar convection heat transfer around lateral perforated fins, Computational Thermal Sciences 1 (2009) 323-340.

[29] Md. F. Ismail, M.N. Hasan, S.C. Saha, Numerical study of turbulent fluid flow and heat transfer in lateral perforated extended surfaces, Energy 64 (2014) 632-639.

[30] A. Willockx, Using the inverse heat conduction problem and thermography for the determination of local heat transfer coefficients and fin effectiveness for longitudinal fins, Doctoral dissertation, Ghent University, 2009.

[31] K.H. Dhanawade, V.K. Sunnapwar, H.S. Dhanawade, Optimization of design parameters for lateral circular perforated fin arrays under forced convection, Heat Transfer-Asian Research 45 (2016) 30-45. [32] K.H. Dhanawade, H.S. Dhanawade, Enhancement of forced convection heat transfer from fin arrays with circular perforation, Frontiers in Automobile and Mechanical Engineering (2010) pp. 192-196, IEEE.

[33] W.H.A.R. Al-Doori, Enhancement of natural convection heat transfer from the rectangular fins by circular perforations, International Journal of Automotive and Mechanical Engineering 4 (2011) 428-436. [34] R. Karabacak, G. Yakar, Forced convection heat transfer and pressure drop for a horizontal cylinder with vertically attached imperforate and perforated circular fins, Energy Conversion and Management 52 (2011) 2785-2793.

[35] D.H. Lee, J.M. Jung, J.H. Ha, Y.I. Cho, Improvement of heat transfer with perforated circular holes in finned tubes of air-cooled heat exchanger, International Communications in Heat and Mass Transfer 39 (2012) 161-166. 
[36] R.K. Banerjee, M. Karve, J.H. Ha, D.H. lee, Y.I. Cho, Evaluation of enhanced heat transfer within a four row finned tube array of an air cooled steam condenser, Numerical Heat Transfer, Part A 61 (2012) 735-753.

[37] X. Liu, J. Yu, G. Yan, A numerical study on the air-side heat transfer of perforated finned-tube heat exchangers with large fin pitches, International Journal of Heat and Mass Transfer 100 (2016) 199207.

[38] M.R. Shaeri, B. Richard, R. Bonner, Cooling performances of perforated-finned heat sinks, HT20167284, ASME Summer Heat Transfer Conference, July 10-14, 2016, Washington, DC.

[39] J. Lee, I. Mudawar, Two-phase flow in high-heat-flux micro-channel heat sink for refrigeration cooling applications: Part II — heat transfer characteristics, International Journal of Heat and Mass Transfer 48 (2005) 941-955.

[40] R.J. Moffat, Describing the uncertainties in experimental results, Experimental Thermal and Fluid Science 1 (1988) 3-17.

[41] T.B. Gatski, C.E. Grosch, Embedded cavity drag in steady and unsteady flows, NASA Contractor Report, 1983.

[42] P. Canhoto, A.H. Reis, Optimization of forced convection heat sinks with pumping power requirements, International Journal of Heat and Mass Transfer 54 (2011) 1441-1447.

[43] S. Ndao, Y. Peles, M.K. Jensen, Multi-objective thermal design optimization and comparative analysis of electronics cooling technologies, International Journal of Heat and Mass Transfer 52 (2009) 4317-4326.

[44] M.E. Steinke, S.G. Kandlikar, Single-phase liquid friction factors in microchannels, International Journal of Thermal Sciences 45 (2006) 1073-1083.

[45] P. Teertstra, M.M. Yovanovich, J.R. Culham, Analytical forced convection modeling of plate fin heat sinks, Journal of Electronics Manufacturing 10 (2000) 253-261. 


\section{Figure captions}

Fig. 1. (a) The CAD model of the experimental setup; (b) the exploded view of the experimental setup.

Fig. 2. The CAD model of the LA-PFHS with two rows of perforations in this study.

Fig. 3. View of bottom of the heat sink, showing grooves required to embed thermocouples and location of thermocouples.

Fig. 4. Unit cell of a channel.

Fig. 5. Comparison of acquired experimental results for the SFHS to widely accepted correlations. (a) pressure drops across the heat sink; (b) Nusselt numbers inside a single channel.

Fig. 6. Pressure drops across the SFHS and LA-PFHSs with perforation sizes at (a) $5.08 \mathrm{~mm}$, (b) 7.62 $\mathrm{mm}$, and (c) $15.24 \mathrm{~mm}$.

Fig. 7. (a) A LA-PFHS with 4 perforations, (b) flow path lines at 30\% height of the LA-PFHS with 4 perforations, (c) flow path lines at 70\% height of the LA-PFHS with 4 perforations, (d) a LA-PFHS with 50 perforations, (e) flow path lines at $30 \%$ height of the LA-PFHS with 50 perforations, (f) flow path lines at $70 \%$ height of the LA-PFHS with 50 perforations. Figure is given from [28].

Fig. 8. Pressure drops across the SFHS and LA-PFHSs with porosities at (a) 0.15, (b) 0.35, and (c) 0.55.

Fig. 9. $R_{\mathrm{ch}}$ at $L_{\mathrm{TC}}=2.54 \mathrm{~cm}$ for the SFHS and LA-PFHSs with perforation sizes at (a) $5.08 \mathrm{~mm}$, (b) 7.62 $\mathrm{mm}$, and (c) $15.24 \mathrm{~mm}$.

Fig. 10. $R_{\mathrm{ch}}$ at $L_{\mathrm{TC}}=6.35 \mathrm{~cm}$ for the SFHS and LA-PFHSs with perforation sizes at (a) $5.08 \mathrm{~mm}$, (b) 7.62 $\mathrm{mm}$, and (c) $15.24 \mathrm{~mm}$.

Fig. 11. $R_{\mathrm{ch}}$ at $L_{\mathrm{TC}}=10.16 \mathrm{~cm}$ for the SFHS and LA-PFHSs with perforation sizes at (a) $5.08 \mathrm{~mm}$, (b) 7.62 $\mathrm{mm}$, and (c) $15.24 \mathrm{~mm}$. 
Fig. 12. $R_{\mathrm{ch}}$ at $L_{\mathrm{TC}}=13.97 \mathrm{~cm}$ for the SFHS and LA-PFHSs with perforation sizes at (a) $5.08 \mathrm{~mm}$, (b) 7.62 $\mathrm{mm}$, and (c) $15.24 \mathrm{~mm}$.

Fig. 13. $R_{\mathrm{ch}}$ at $L_{\mathrm{TC}}=17.78 \mathrm{~cm}$ for the SFHS and LA-PFHSs with perforation sizes at (a) $5.08 \mathrm{~mm}$, (b) 7.62 $\mathrm{mm}$, and (c) $15.24 \mathrm{~mm}$.

Fig. 14. Heat sink thermal resistance for the SFHS and LA-PFHSs with perforation sizes at (a) $5.08 \mathrm{~mm}$, (b) $7.62 \mathrm{~mm}$, and (c) $15.24 \mathrm{~mm}$.

Fig. 15. Percentage of changes in $R_{\mathrm{HS}, \mathrm{SFHS}}$ by LA-PFHSs. Each porosity includes three perforation sizes of $5.08 \mathrm{~mm}, 7.62 \mathrm{~mm}$, and $15.24 \mathrm{~mm}$.

Fig. 16. Normalized temperature non-uniformity across the heat sink bases for the SFHS and LA-PFHSs with a perforation size at (a) $5.08 \mathrm{~mm}$, (b) $7.62 \mathrm{~mm}$, and (c) $15.24 \mathrm{~mm}$.

Fig. 17. Percentage of changes in MBTR SFHS $_{\text {by }}$ LA-PFHSs. Each porosity includes three perforation sizes of $5.08 \mathrm{~mm}, 7.62 \mathrm{~mm}$, and $15.24 \mathrm{~mm}$. 


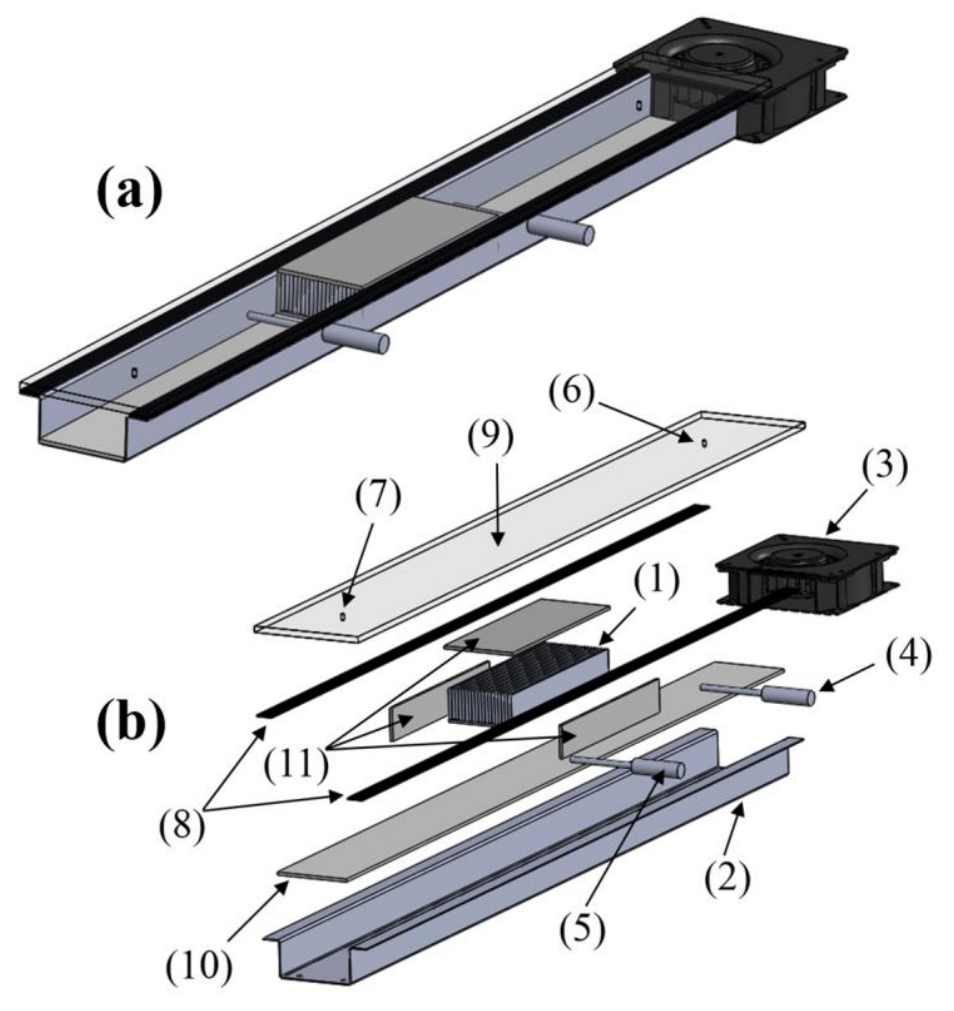




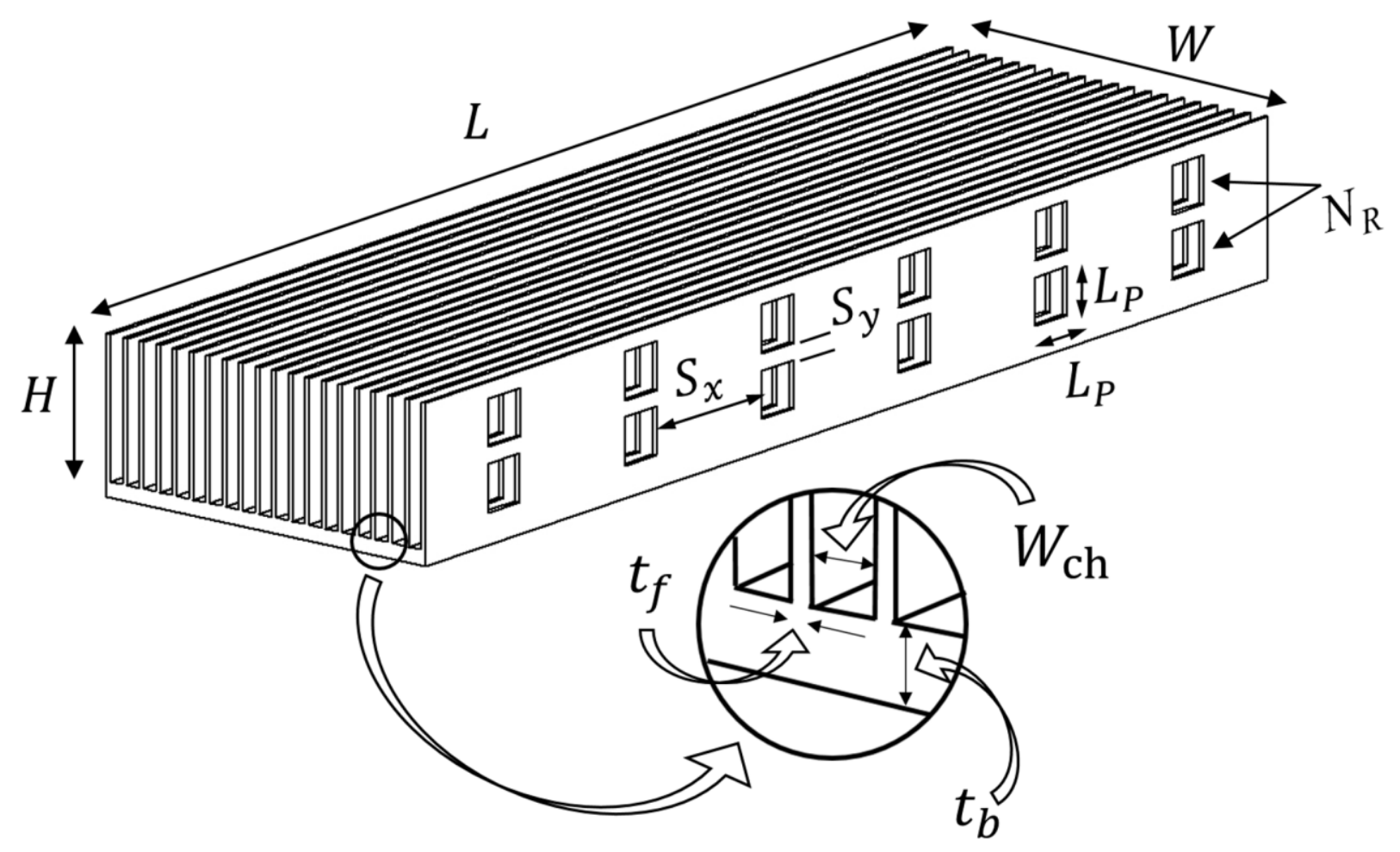




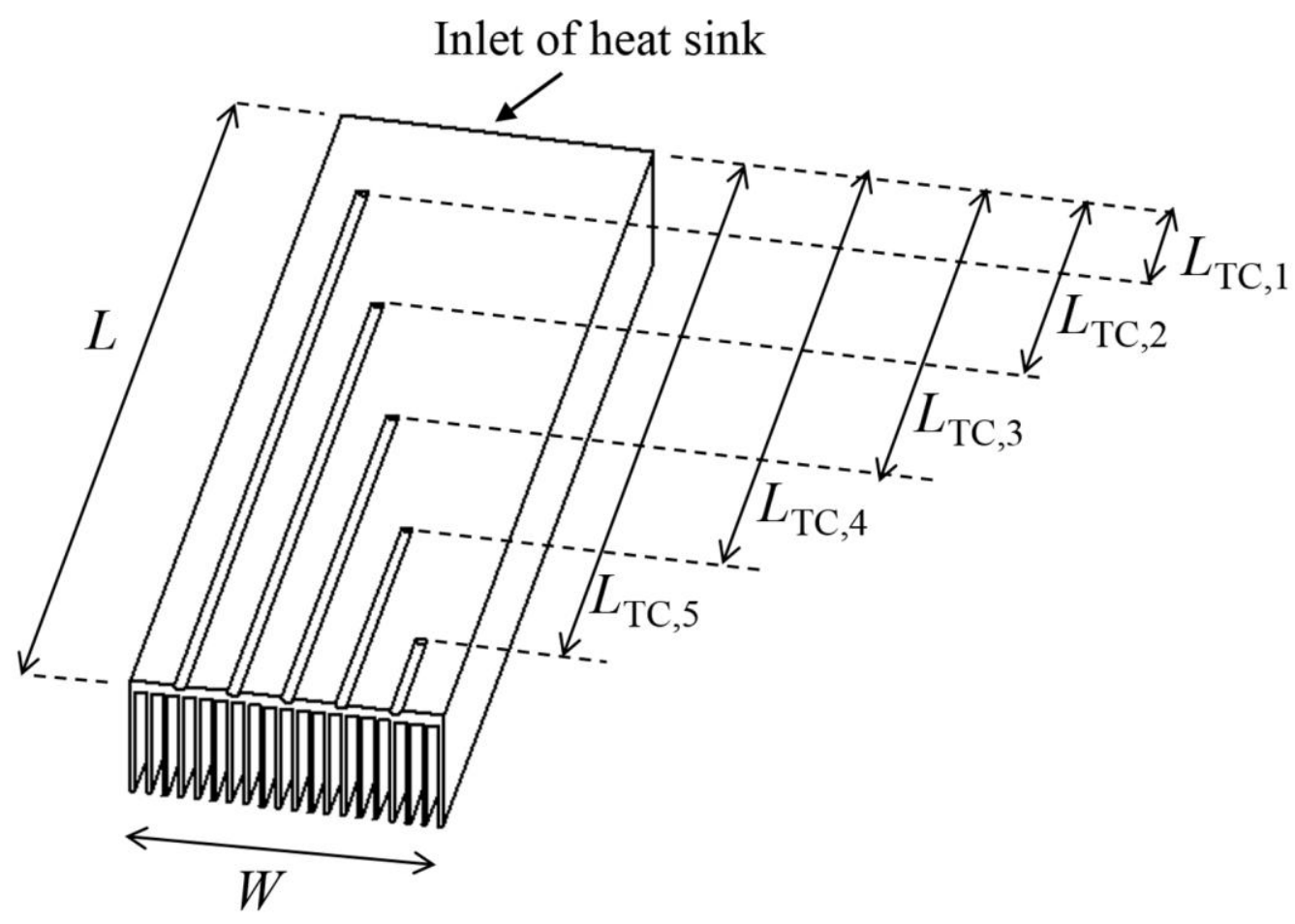




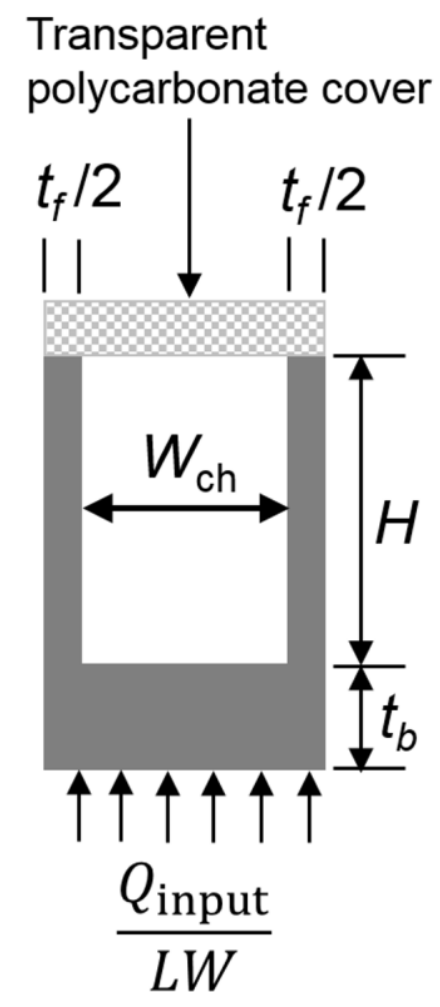




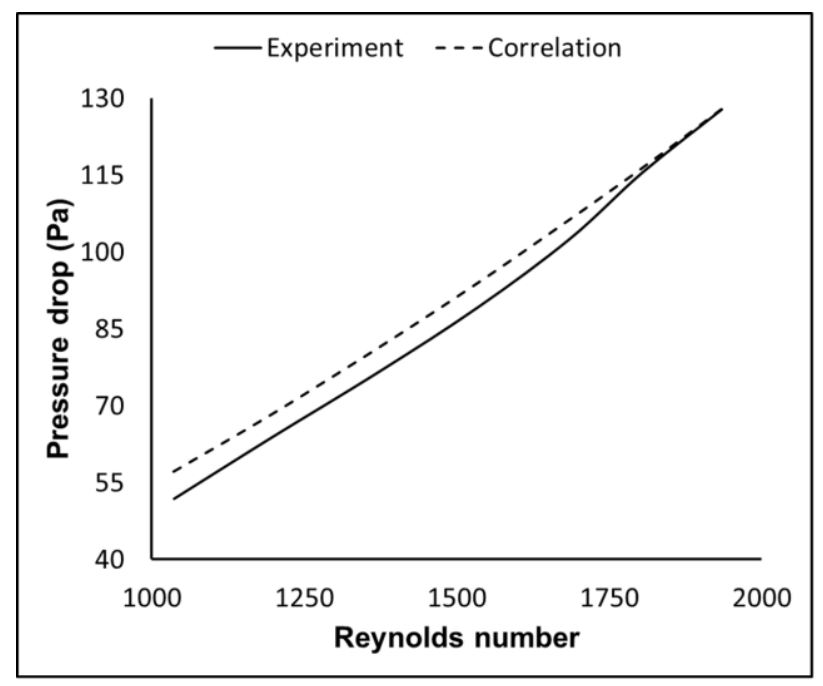

(a)

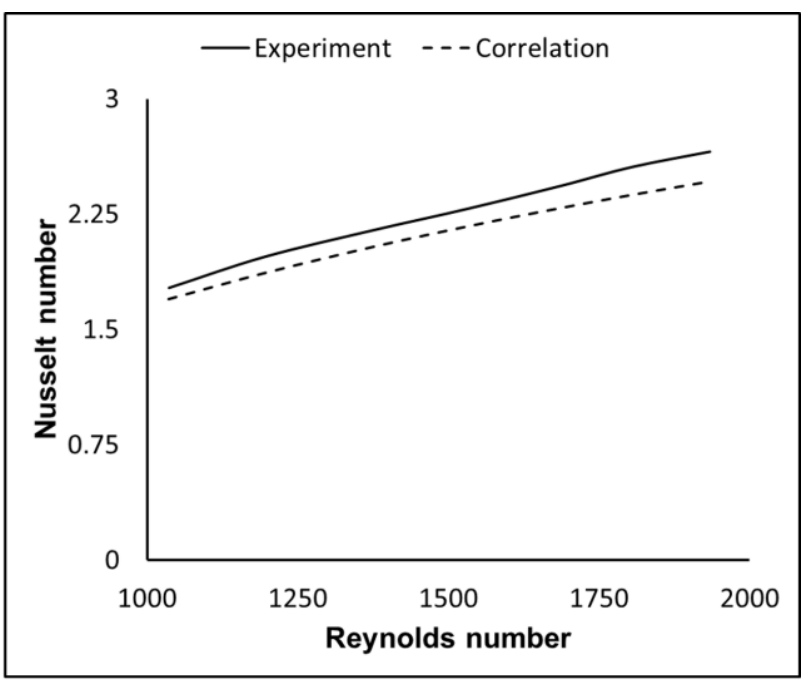

(b) 


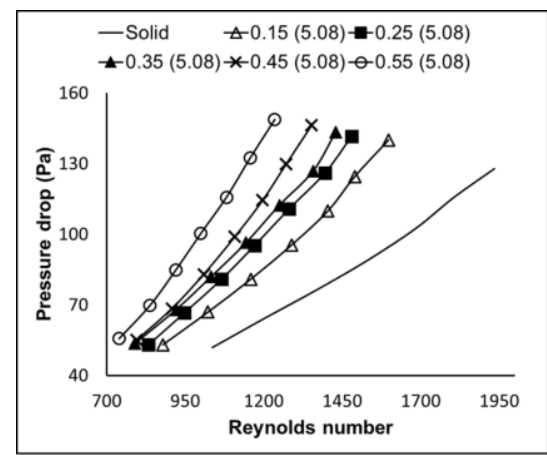

(a)

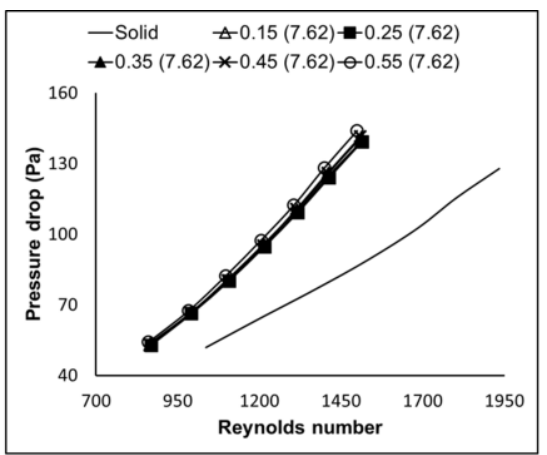

(b)

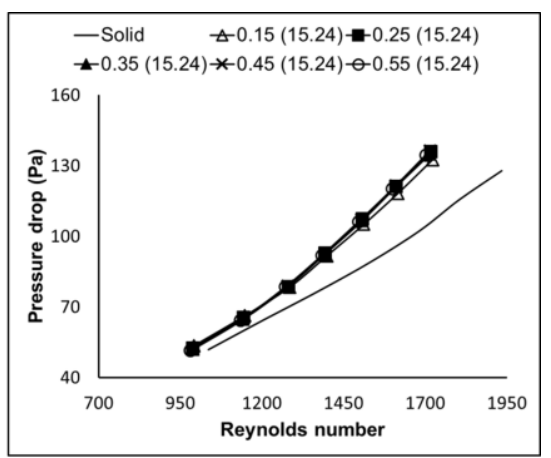

(c) 


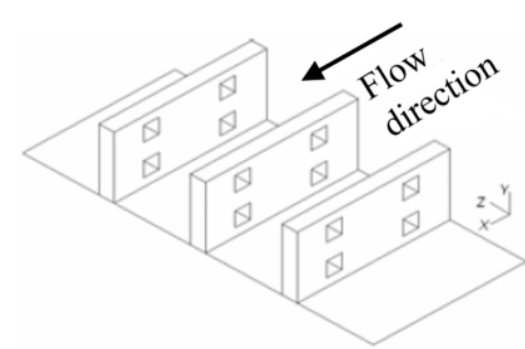

(a)

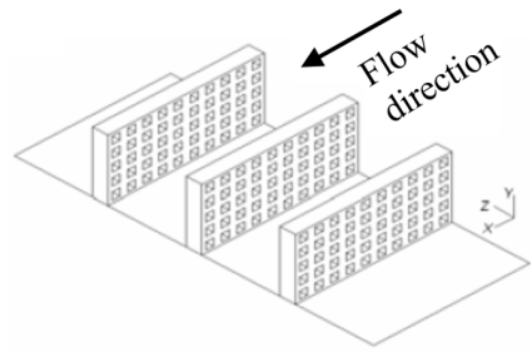

(d)

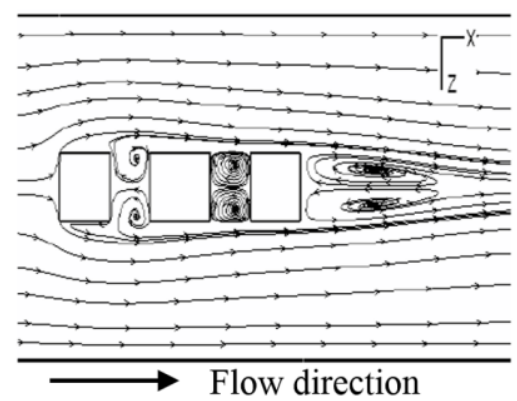

(b)

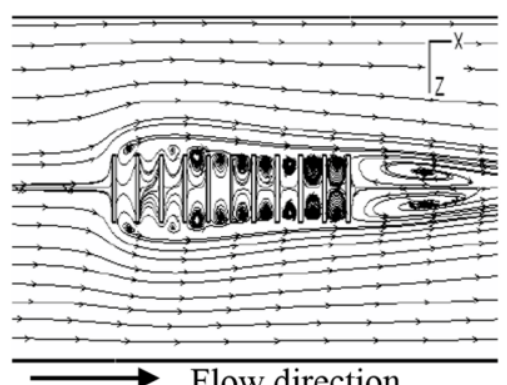

(e)

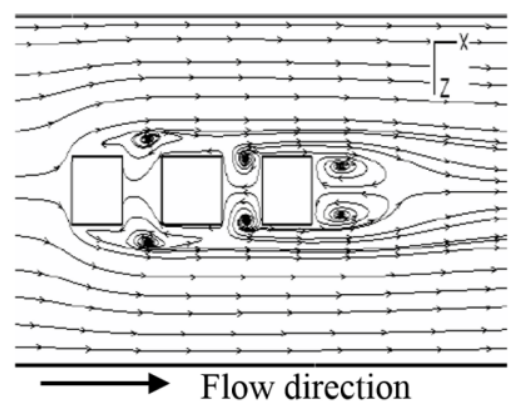

(c)

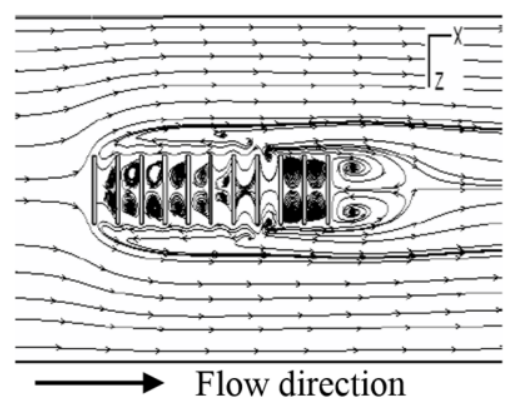

(f) 


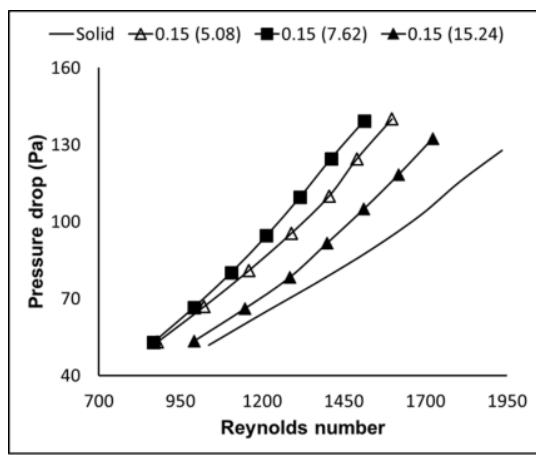

(a)

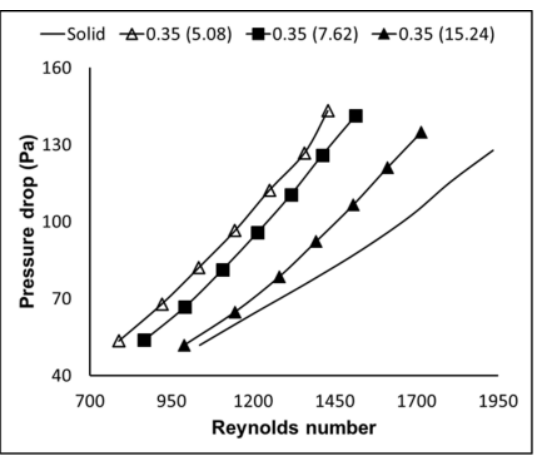

(b)

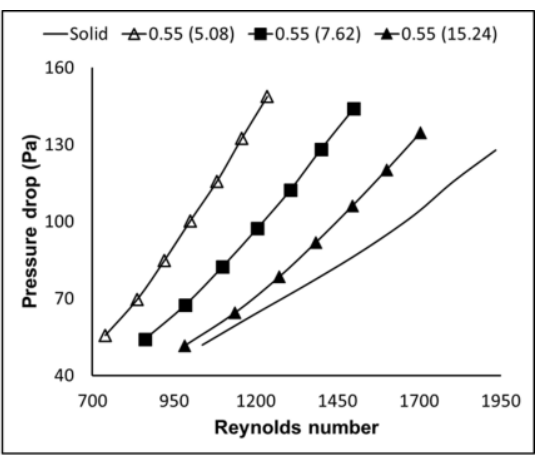

(c) 


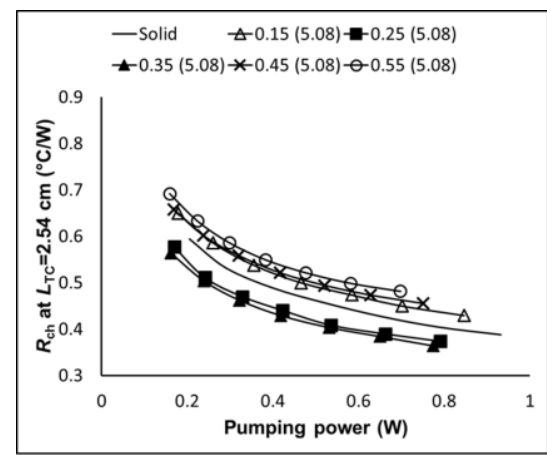

(a)

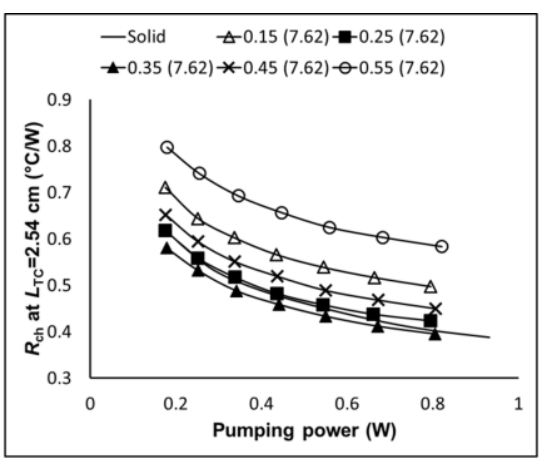

(b)

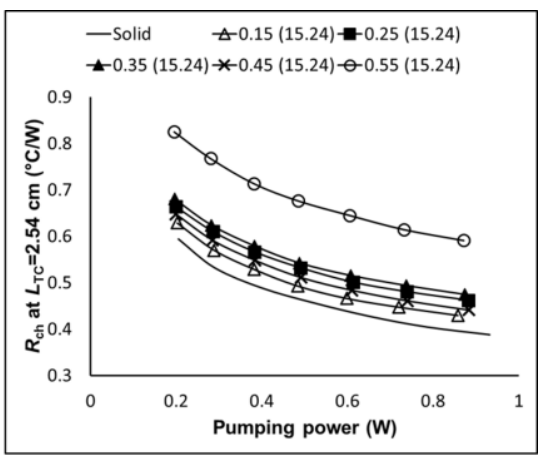

(c) 


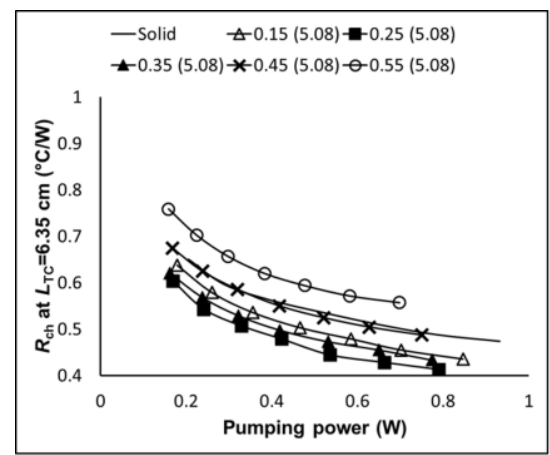

(a)

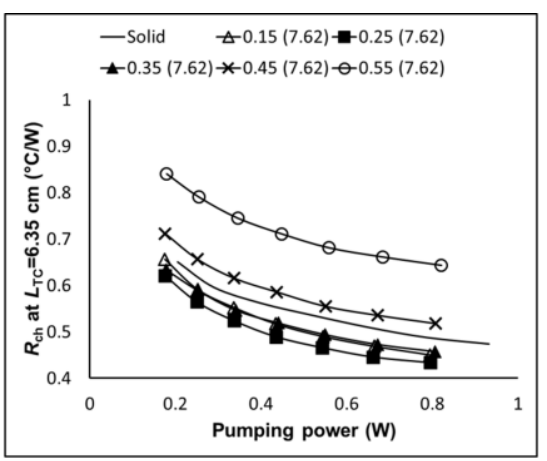

(b)

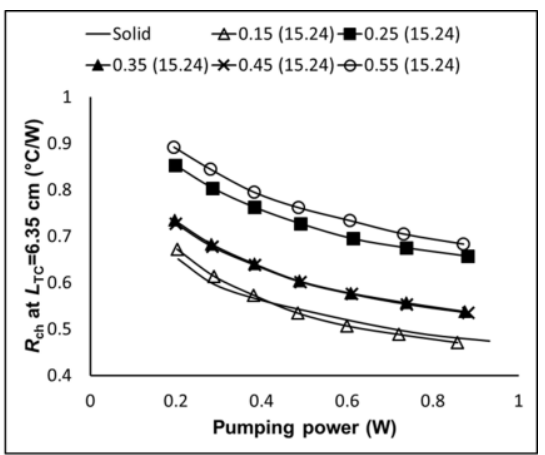

(c) 


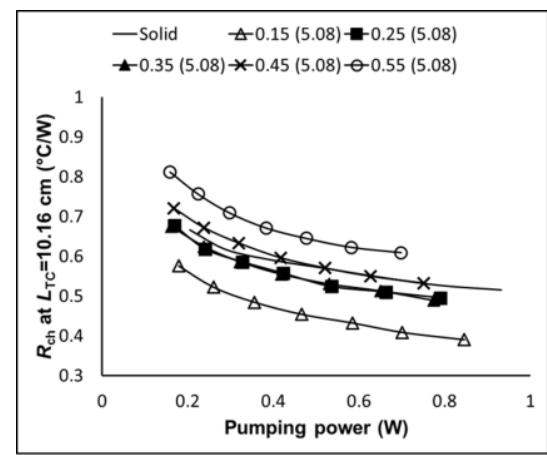

(a)

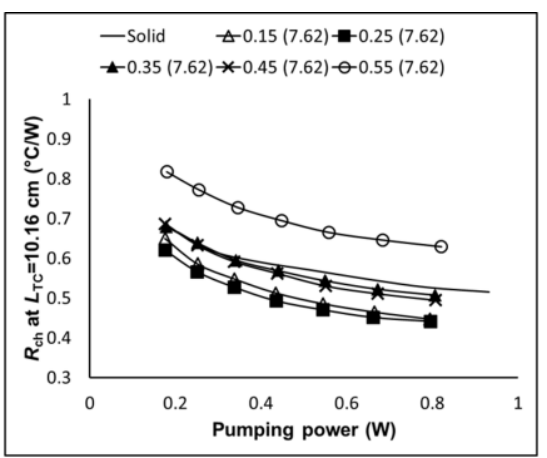

(b)

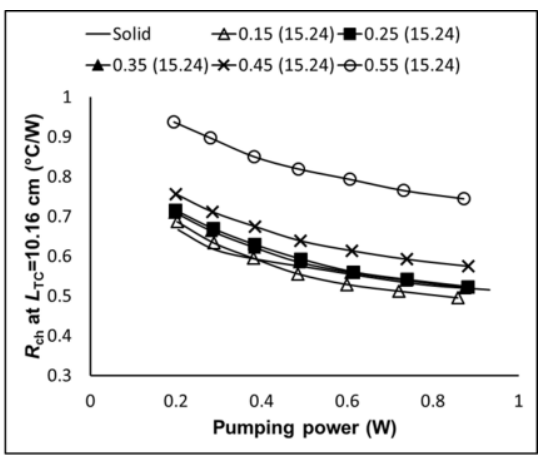

(c) 


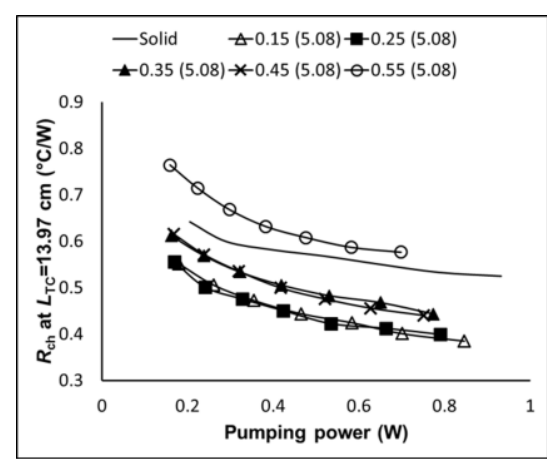

(a)

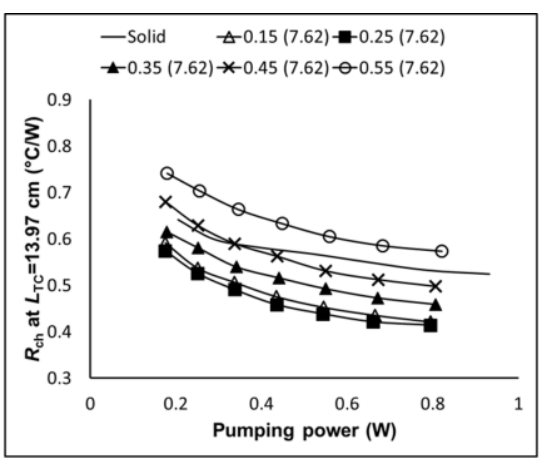

(b)

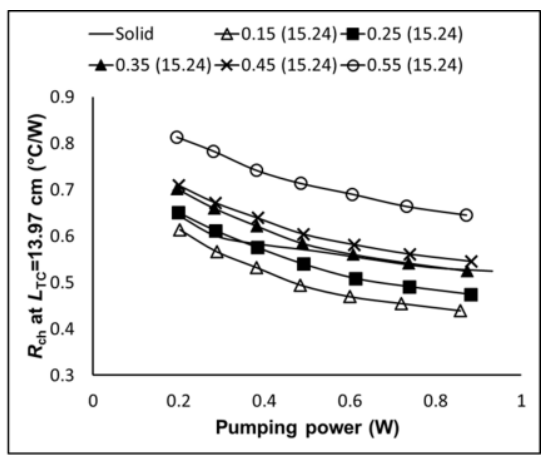

(c) 


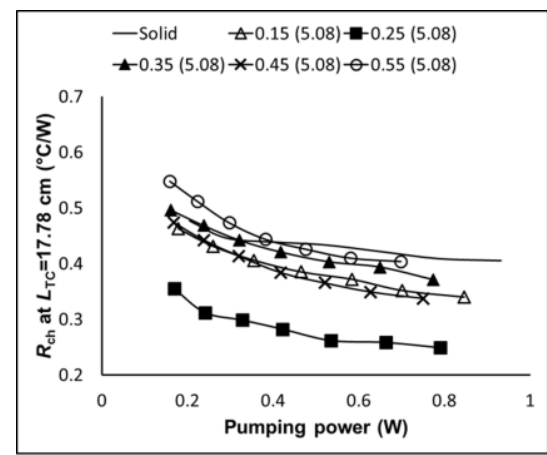

(a)

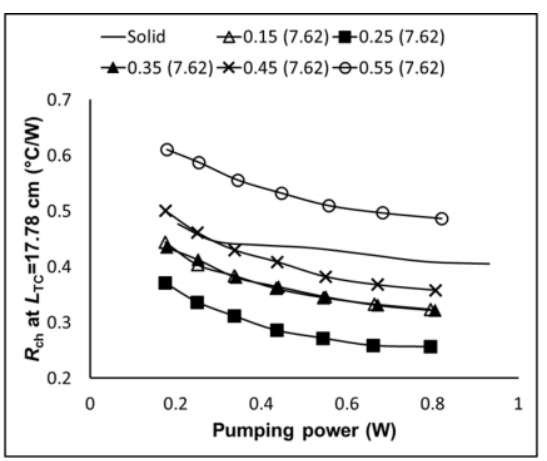

(b)

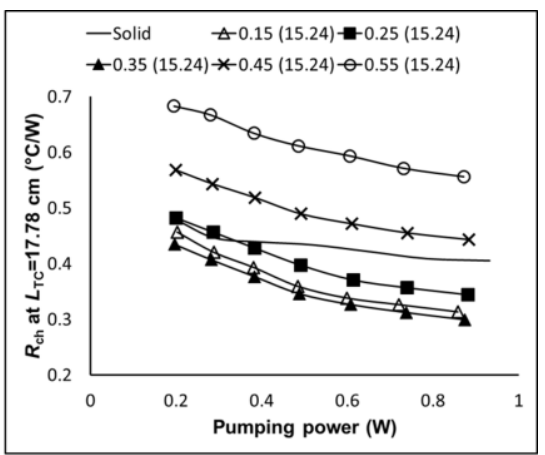

(c) 


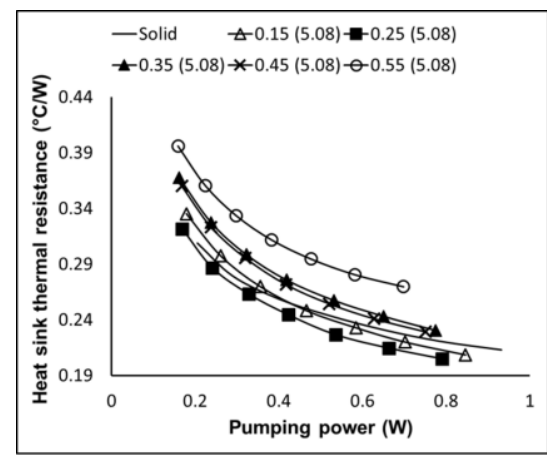

(a)

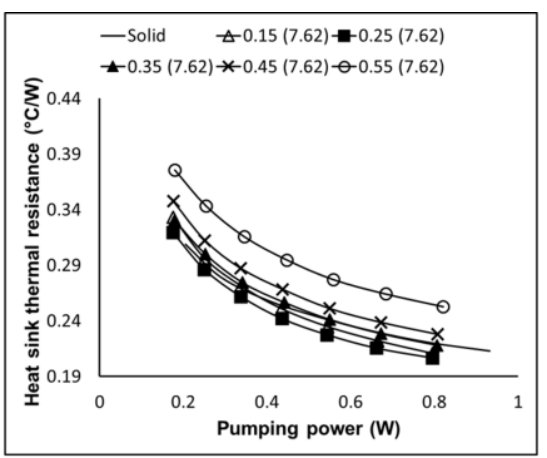

(b)

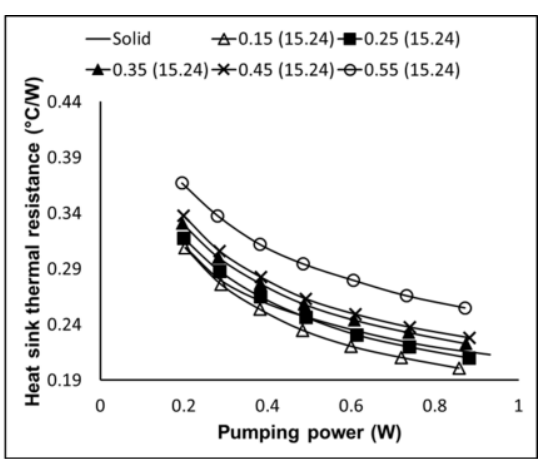

(c) 


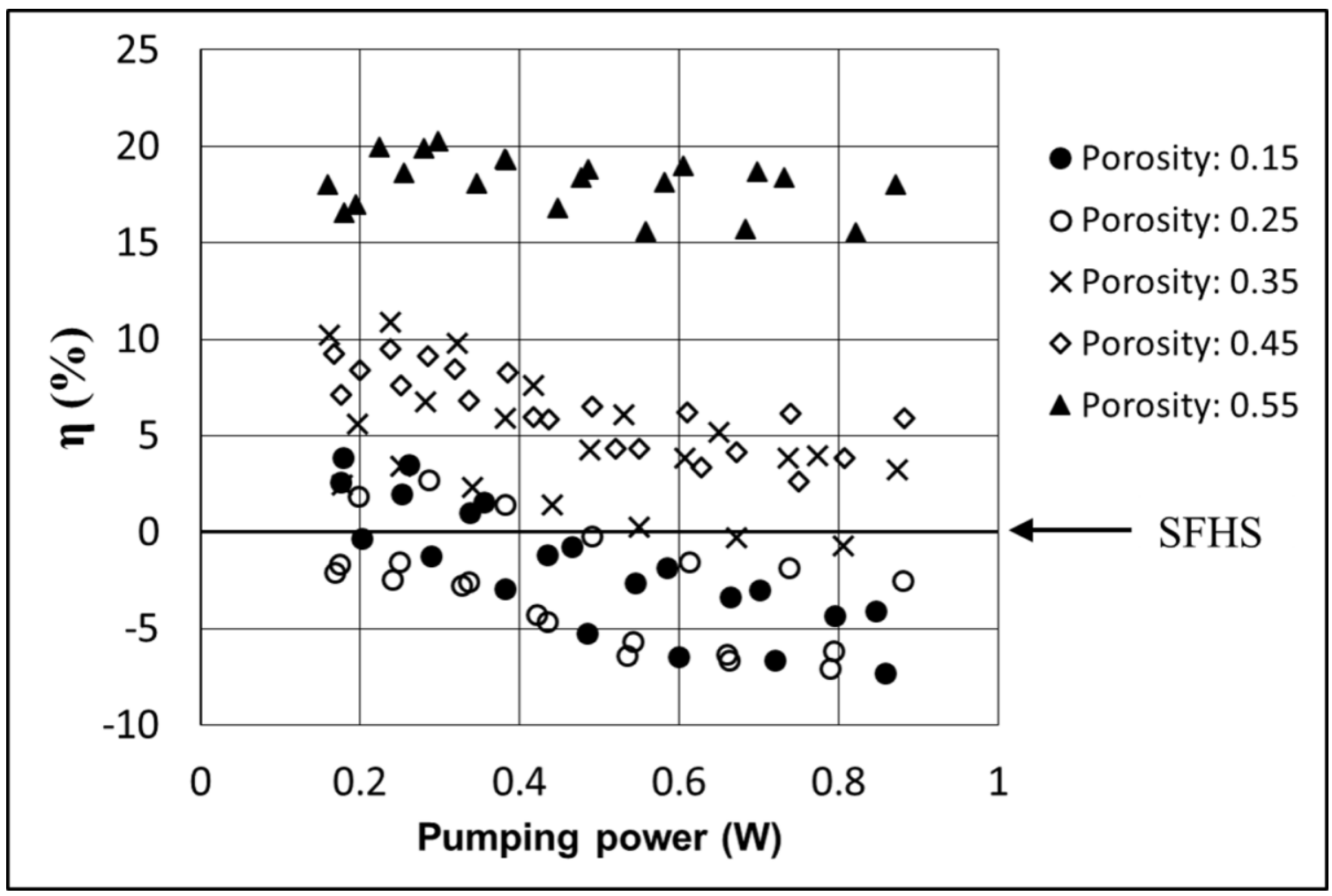




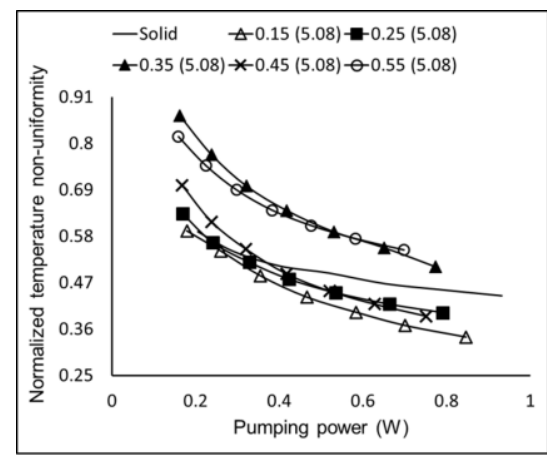

(a)

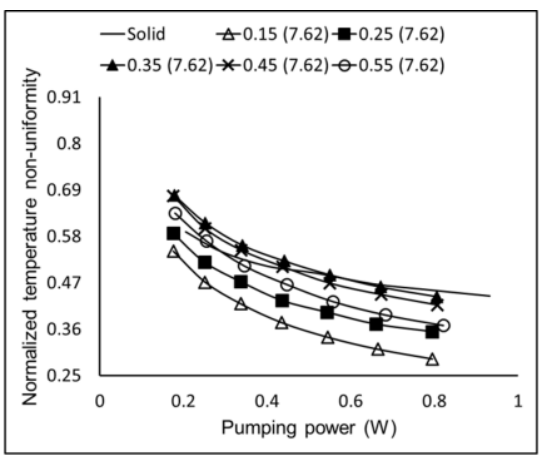

(b)

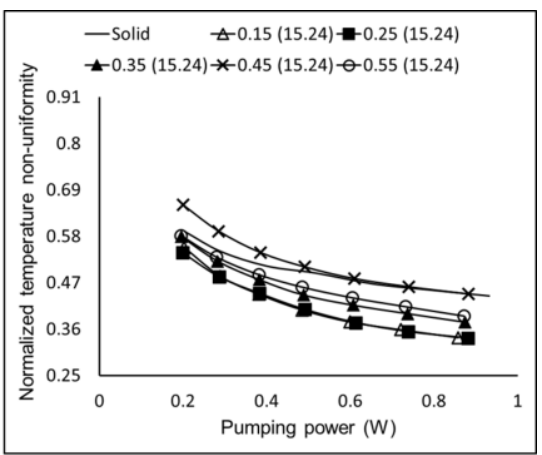

(c) 


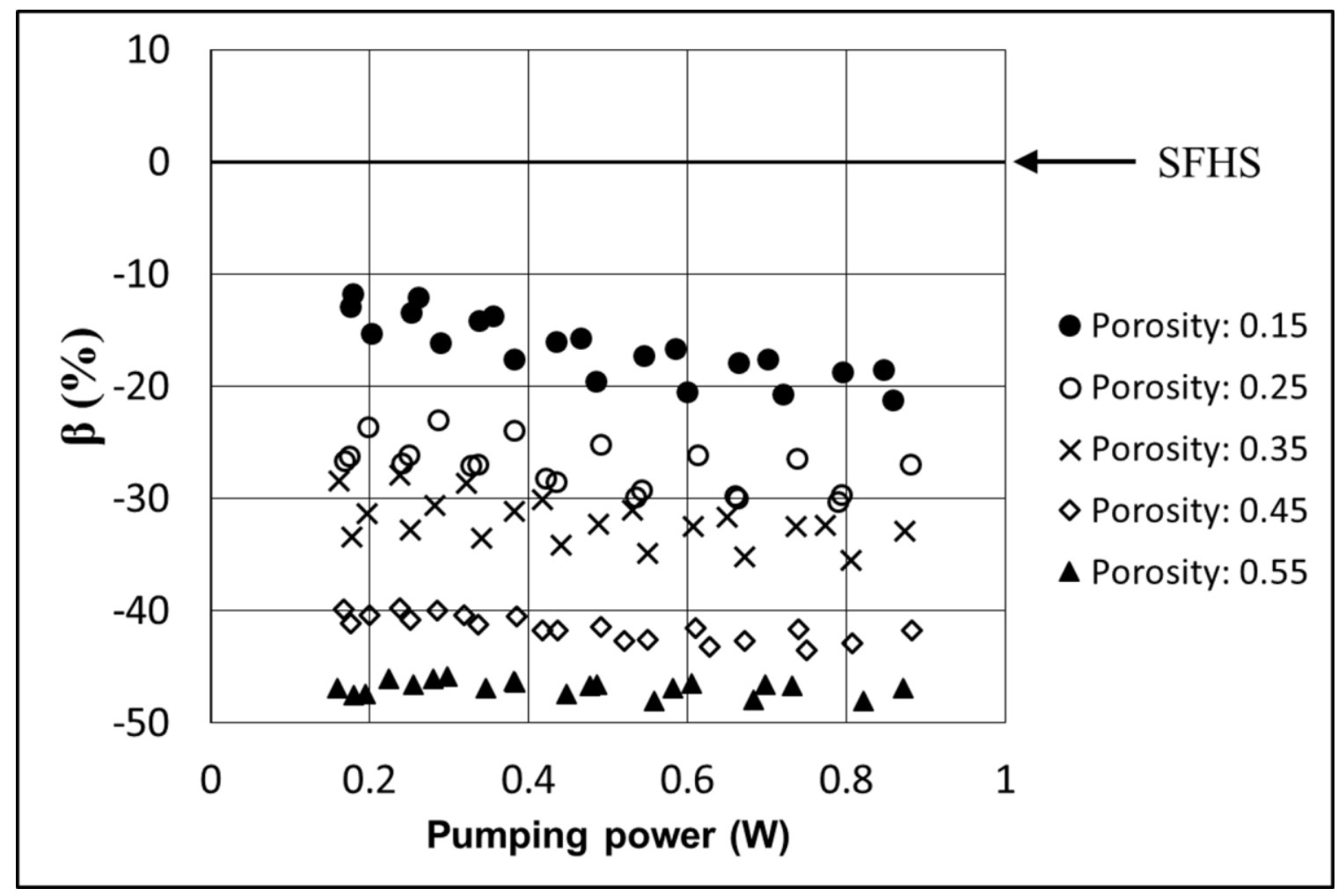

